\title{
Generación y transformación de las instituciones sociales: los procesos morfoestáticos y los procesos morfogenéticos
}

\author{
Manuel Herrera Gómez \\ Universidad de Granada \\ mherrera@ugr.es \\ Antonio M. Jaime Castillo \\ Universidad de Granada \\ amjaime@ugr.es
}

RESUMEN

En este artículo se analizan las dinámicas de generación y transformación de las instituciones sociales. Se estudian y confrontan dos paradigmas fundamentales. Las teorías utilitaristas o de la elección racional, según las cuales las instituciones son un intento de superación de los fallos del mercado a través de mecanismos institucionales que conduzcan a situaciones socialmente óptimas, en el sentido de ser preferibles para los actores individuales implicados. Las teorías de carácter más sociológico o culturalista, por el contrario, ponen de relieve el componente cultural de las instituciones, así como sus determinantes sociohistóricos que se decantan a través de procesos sociales complejos. Mientras las primeras proveen soluciones contrastables teóricamente para un rango de problemas limitados, las segundas analizan problemas de mayor calado aun a riesgo de producir resultados menos concluyentes. En particular, las diferencias entre ambas concepciones de las instituciones sociales se hacen evidentes al analizar los factores que dan origen al desarrollo de las instituciones, así como de los procesos a través de los cuales cambian y evolucionan los marcos institucionales en respuesta a diferentes factores.

Palabras clave: Instituciones Sociales, Normas Culturales, Elección Racional, Cambio Social. 


\section{INTRODUCCIÓN. INSTITUCIONES Y ORDEN SOCIAL}

Si preguntamos al hombre de la calle qué entiende con el término «institución», probablemente la respuesta será la siguiente: un ente, un aparato, un sistema que establece la sociedad para conseguir determinados fines; algo que funciona de por sí, según sus lógicas, y que mantiene una cierta distancia de la acción y de la voluntad de los individuos. Puede incluso llegar a decir que es algo a lo que se asocia un sentido de prestigio y de gran importancia para la vida de todos; o bien, y no es extraño, nuestro interlocutor evocará una cierta idea de limitación, de acciones iguales que se repiten y que esconden la sensación de rigidez. Si, posteriormente, le pedimos que nos indique algunas realidades concretas que podrían ser definidas como «instituciones», seguramente aludirá al Estado y sus articulaciones, a la política, a la burocracia. Podrá incluso añadir entidades como la escuela, la Universidad, la Iglesia o el sistema sanitario. Quizás cite el matrimonio, y lo más seguro es que no tenga presentes a los contratos con los que se llevan a cabo los intercambios comerciales o una disciplina científica.

La Sociología atribuye el concepto de institución a todas las entidades apuntadas y a otras muchas. De la misma manera que otras ramas de las Ciencias Sociales, como la Economía, la Ciencia Política o el Derecho, sostienen otras tantas definiciones del concepto de institución social. Ahora bien, ¿cómo es posible y qué sentido tiene mantener unidas realidades tan diversas? ¿Qué es lo que hace de todas estas realidades una institución?

En el Prefacio a la segunda edición de las Reglas del método sociológico (1912: XXII), Émile Durkheim considera a la Sociología como la "ciencia de las instituciones, de su génesis y de su funcionamiento». De esta forma, según el sociólogo francés, el término institución expresa la peculiar y propia forma de ser de los fenómenos sociales. Dentro de la tradición funcionalista, la existencia de instituciones siempre ha sido considerada como algo que está inserto en la misma naturaleza de la sociedad. En este sentido, las instituciones han sido definidas como el más general de los universales evolutivos de la historia de la sociedad humana (Parsons, 1964), y una de sus cualidades emergentes en cuanto diferente de la pre y no humana. La Sociología siempre ha hablado de instituciones. Sin embargo, la teoría de las instituciones se ha desarrollado muy poco y de forma controvertida.

Como veremos, esto se debe a motivos nada superficiales. Por ello, nuestro punto de partida no será dar una definición de institución. Consideramos más fecundo partir de una conexión fundamental que identifique algunos de los problemas respecto a los que interrogar y desarrollar la teoría sociológica. Y el nexo fundamental y originario es aquel entre instituciones y orden social. A partir de él, la teoría de las instituciones también es un teoría de la génesis, del cambio y de la cualidad del orden social. 
La posibilidad del orden social es el problema que define a la misma Sociología en cuanto disciplina científica (Simmel, 1986; Parsons, 1988; Luhmann, 1998). En la historia del pensamiento social occidental, tal cuestión se ha hecho operativa a través de su descomposición en dos diferentes interrogantes:

a) La cuestión de las relaciones entre personas: ¿cómo es posible que personas diferentes entre sí puedan anudar relaciones regulares, relativamente estables?

b) La cuestión de las relaciones entre individuo y colectividad: ¿cómo son posibles relaciones distanciadas de la situación actual, que permitan la emergencia de realidades sociales particulares?

Este intento de simplificación está legitimado tanto por la necesidad teórica como por el hecho de reflejar la experiencia humana de lo social, que efectivamente comporta una duplicidad de lógicas y de contextos de este género. Sin embargo, dada su multiplicidad, ha abierto el grave problema de la unidad de lo social. Tal operación conceptual implica la idea de que «lo social no es uno e indivisible, sino que está constituido de elementos heterogéneos» (Archer, 1995: 122). Dicho en otros términos: si lo social se distingue (y solamente se hace observable) en los dos fenómenos anteriores, a) y b), ¿cuál es la unidad de esta diferencia? ¿Qué es lo que permite que entre ambos se pueda hablar de orden social y de sociabilidad? El dilema del orden social es resuelto mediante una insuficiente «visión estratificada» respecto a la unidad. Ciertamente, la realidad social está estratificada interiormente. Sin embargo, debe ser una unidad de la diferencia, algo que denomina lo social en todos los niveles de «su» estratificación.

La Sociología nace cuando son consideradas como insuficientes las soluciones filosóficas y jurídicas. Sin embargo, una descomposición sociológicamente adecuada de la fórmula general aún sigue siendo un objetivo a realizar. Por ahora, la respuesta a cómo es posible el orden social debe ser subdivida en diferentes segmentos teóricos. Se podría responder: a) mediante el sentido; b) mediante la formación de sistemas sociales que puedan durar manteniendo límites estables en las confrontaciones de un ambiente supracomplejo; c) mediante evolución sociocultural (Luhmann, 1998).

Estas tres respuestas tienen que ver directamente con las instituciones. Por tanto, el problema de las instituciones está en el cruce de las diferentes dimensiones temáticas, en la intersección tanto de las formulaciones planteadas por la teoría como de estas tres direcciones de respuesta. Por este motivo, en estas páginas se expondrán los problemas de la génesis y del cambio institucional. 
Un elemento fundamental y general debe tenerse presente en el planteamiento específicamente sociológico respecto al problema del orden social. La Sociología nace como crítica a las concepciones utilitaristas e individualistas del orden social (Parsons, 1968) ${ }^{1}$. Y es en este contexto teórico donde emerge y se elabora el concepto de institución. La idea de institución aparece en la teoría sociológica para comprender y explicar un orden social que no puede ser reducido a la sola agregación más o menos inmediata, espontánea o planificada de las acciones de individuos particulares².

Dos son las tradiciones de pensamiento que pueden identificarse claramente en el reciente tratamiento de las instituciones. El primero de estos planteamientos es el que se desarrolla inicialmente alrededor de la tradición económica y que se conoce habitualmente como reduccionista. Su base es el individualismo metodológico, el paradigma de la elección racional y, generalmente, su método de análisis es la teoría de juegos. En este esquema, las instituciones tienen un carácter exógeno y los diseños institucionales se definen como un marco de constricciones sobre la acción individual. El segundo planteamiento, de matriz fundamentalmente sociológica, entiende las instituciones como un fenómeno endógeno, considerando que los diseños institucionales son el propio resultado de dinámicas sociales complejas. En este sentido, su preocupación fundamental es el estudio del origen mismo de las instituciones (Van Hess, 1997).

De forma más o menos directa, existe una amplia literatura alusiva al fenómeno institucional. Naturalmente, la confrontación con la mediación de los autores más relevantes de la teoría sociológica será imprescindible. Sin embargo, exploraremos el nexo entre instituciones y orden social aludiendo a algunos problemas cruciales. Los ejes de nuestras argumentaciones son tres: en primer lugar, abordaremos el problema de la concepción de las instituciones desde la perspectiva sociológica; a continuación, nos ocuparemos de cómo se generan las instituciones y, por último, de su transformación. Esta secuencia no es «causal» ni cronológica. Refleja la necesidad del nexo entre ontología social, metodológica explicativa y teoría práctica (Archer, 1995).

Transversalmente a los anteriores problemas —la definición, la génesis y el cambio- están dos cuestiones conceptuales que definen las coordenadas teóricas con las que se orientan nuestros argumentos:

\footnotetext{
1 Esto no ha impedido que la disciplina haya mostrado, y aún muestre, dificultades para distanciarse de ellas. Una idea clara de esta cuestión nos la ofrece Archer (1995: caps. 1-3).

2 Por ejemplo, es conocida la centralidad del problema del orden en la sociología de Durkheim. El concepto alude a formas de pensar y de obrar instituidas, en el sentido de externas e impuestas al individuo. Análogamente, el reciente revival de la atención por la realidad institucional, que ha dado lugar a un filón de estudios definido como «neo-institucionalismo» (Powell y Di Maggio, 1991; Lanzalaco, 1995). A diferencia del institucionalismo clásico, el nuevo institucionalismo no es de raíz estructuralista.
} 
a) El nexo entre estructura y acción: que alude a la relación que conecta estructura y acción, teleología y casualidad, determinismo y libertad, en la construcción y en la dinámica institucional. Nuestra tesis es que la teoría sociológica sólo puede comprender plenamente el fenómeno institucional humano integrando tales factores.

b) El tipo de procesos generativos: que comporta una visión plural y compleja de las lógicas y de los recorridos diferenciados a través de los cuales las instituciones se generan y transforman.

En ambas coordenadas las cuestiones se declinan de forma diferente en el ámbito de los concretos temas de cada apartado. En su conjunto, y desde un punto de vista específico, el artículo presenta un cuadro de síntesis e intenta realizar un balance de los resultados alcanzados y de los problemas de una teoría dinámica de las instituciones. En concreto, al final de estas páginas, nuestro objetivo es presentar al lector dos grandes ideas: que la capacidad de formular de forma satisfactoria las anteriores cuestiones (de la estructura y de la acción, y de los procesos generativos) y de integrarlas en un planteamiento generalizado es actualmente la frontera teórica más cualificada en la que está comprometida la Sociología, y que tal frontera sólo puede cruzarse desarrollando un planteamiento relacional a la fenomenología del orden social.

\section{2. ¿QUÉ ES UNA INSTITUCIÓN SOCIAL?}

Una definición del término institución generalmente comporta la idea de complejos normativos que regulan los comportamientos de los individuos aludiendo a aspectos relevantes de la vida social, reduciendo las alternativas abiertas a los sujetos, y con ello la complejidad y la contingencia de la sociedad (Gallino, 1993: 389). De forma articulada, se puede aludir a los siguientes elementos (Cavalli, 1996: 122-134):

1. Las instituciones son modelos de comportamiento dotados de normatividad.

2. Que tienen una duración temporal (mayor respecto a los individuos).

3. Y cuya dinámica es resultado de la intersección de procesos espontáneos y queridos, que reflejan las necesidades y los requisitos funcionales de la sociedad.

Institución es un término que tiene su origen etimológico en la raíz indoeuropea esta, que posee dos significados: a) estar, permanecer (aquello que objetivamente «está», dura, no cambia); b) poner, colocar (acción encaminada a hacer que algo no cambie, permanezca o 
sea estable). Por tanto, expresa al mismo tiempo una constatación ontológica de regularidades existentes en el mundo y una voluntad humana de introducir en aquel mundo regularidades no existentes. El latín deriva de tal raíz tanto el verbo stare como el verbo sistere. De ahí statuere, constituere, instituere, y los sustantivos statutum, constitutio e institutio. En consecuencia, un significado primordial del término es: "aquello que está, dura, ya sea de por sí (es decir, en cuanto correspondiente a regularidades "naturales", presentes en el mundo), ya sea debido a la acción humana».

Esto introduce un dilema que incluso llega a estar presente en la actualidad: el pensamiento clásico, en la formulación aristotélica, lo entendió como problema de la artificialidad o de la naturalidad de las instituciones. El dilema se reformula en su declinación moderna -antropológica y sociológica-: ¿las instituciones se conectan a los aspectos fundamentales de la experiencia social y existencial humana, y los reflejan, o, al contrario, es la misma realidad la que, en las instituciones, se rebela contra una construcción social humana, pero que en última instancia es un orden ficticio y convencional, y por ello totalmente contingente, que puede cambiar sin vínculos ni límites? Por tanto, el estudio de las instituciones, ¿es una especie de ejercicio de distanciamiento del mundo, en cuanto que lo descubre instituido - fruto de convenciones - incluso en sus aspectos aparentemente naturales, o bien es un camino para su desvelamiento?

Estas valencias y este problema están en la trastienda del pensamiento social occidental. A partir de aquí se perfila la cuestión de la regularidad-estabilidad, es decir, de la naturaleza de lo que regulariza y estabiliza los comportamientos sociales y coordina las acciones humanas para hacer emerger formas de vida social ordenadas. La cuestión se especifica en los siguientes términos:

a) La naturaleza normativa y/o cognitiva de los procesos que generan tal orden.

b) La naturaleza instrumental o constitutiva de los procesos ordenadores y de las formas institucionales que resultan.

Podemos aclarar estas dos dimensiones y reformularlas como dos distinciones. En torno a ellas organizaremos este apartado: se puede hablar de una concepción instrumental/constitutiva (o individualista/holista) y de una concepción normativa/cognitiva de las instituciones. En ellas se expresan y especifican las cuestiones de la estructura y de la acción, y de los procesos generativos planteados en el anterior apartado.

En un cierto sentido, la distinción instrumental/constitutiva define el límite entre teoría sociológica propiamente dicha y otras teorías de las instituciones. ¿Qué debemos entender 
por concepción instrumental de las instituciones? La idea fundamental es la siguiente: las instituciones son mecanismos para la resolución de problemas, que los individuos construyen ad hoc, para servir a algunos fines e intereses propios. Las instituciones, por tanto, se reducen a las «reglas del juego", reglas operativas que indican lo que se debe y no se debe hacer, qué se puede hacer y qué se puede esperar. Las reglas son acordadas por los mismos individuos entre sí, emergen y se afirman de forma inmediata y no problemática en los pequeños grupos, se mantienen mediante incentivos selectivos en los grupos más numerosos y cambian cuando los individuos deciden que no son útiles o eficientes para la consecución del objetivo (North, 1993; Olson, 1992; Ostrom, 1991).

Esta concepción de las instituciones, derivada de la teoría económica, aunque ciertamente extraña a la avenida central de la teoría sociológica, ha provocado un verdadero aluvión de críticas. Los sociólogos tienden a afirmar que explica por qué las reglas institucionalizadas se vinculan a la acción, pero no por qué y cómo los actores están motivados para actuar conforme a las normas. Explicar la conformidad con la convención, la coerción y la conveniencia implica negar el hecho de que frecuentemente se nos pide que nos adaptemos a normas para las que no tenemos ninguna conveniencia personal. Por otra parte, presenta un problema de regresión al infinito, en cuanto que no explica dónde nace la motivación de quien debe ejercer la coerción. Además, concebir las instituciones como fundadas en el cálculo o en la coerción las deslegitima y reduce la conformidad, produciendo la expectativa de su contingencia. Sobre esta base, de hecho, jamás conseguiríamos estabilizar la acción; por tanto, no podrían funcionar (Alexander, 1990a; Lanzalaco, 1995; Parsons, 1990).

Una concepción de este género es propia de las teorías de la elección racional que, procedentes de la Economía, recientemente han tenido una amplia difusión en el ámbito sociológico. Ahora bien, es necesario subrayar la neta contraposición entre tales planteamientos y los propiamente sociológicos (y politológicos), incluidos los recogidos en el marco del «institucionalismo" y de la teoría de la organización de orientación sociológica (Lanzalaco, 1995; March y Olsen, 1997; Powell y Di Maggio, 1991; Zucker, 1988, 1991). Ha correspondido a estos autores observar que:

- No se puede afirmar que los individuos escogen libremente entre las instituciones: más bien las «encuentran», por así decir, en la propia vida.

- Las elecciones individuales no pueden comprenderse al margen de la estructura histórica y cultural de la que forman parte.

- La plasticidad de las instituciones no debe minusvalorarse: las instituciones no se desarrollan simplemente respondiendo a criterios de eficiencia y adaptándose a los intereses individuales. 
La antítesis consiste en una concepción constitutiva opuesta a una instrumental de las instituciones: estas últimas no son meros instrumentos que construyen los individuos para resolver los problemas, sino que endógenamente plasman las preferencias y dan sentido a la acción. Constituyen, en un cierto sentido, la trama y el contexto de la vida social. Los institucionalistas han subrayado cómo en la definición de qué «hace» una institución son cruciales los procesos cognitivos y culturales.

La crítica a la concepción instrumental de las instituciones camina en una dirección diferente. Sin embargo, una visión constitutiva implica para la teoría sociológica dos grandes problemas. El primero corresponde al determinismo insertado en una posición que, de individualista-instrumental, se convierte en holista-constitutiva. Si las instituciones determinan las elecciones, las preferencias, las mismas categorías del pensamiento del individuo, ¿qué hay de la libertad y de la creatividad del actor? Y en el nivel empírico, ¿cómo explicar el efecto - más o menos intencional, pero relevante- de algunos individuos y de sus acciones no determinadas por cualquier lógica estructural conocida sobre la dinámica institucional? El hecho de que el individuo esté insertado en redes y roles institucionales, y en círculos sociales complejos, no implica de por sí la salida de una lógica determinista. La acción humana tan sólo sería la suma, con las correspondientes tensiones que comporta, de diferentes determinismos estructurales. El camino para resolver el dilema individualismo/ holismo (u holismo/reificación) tiene que ser necesariamente más complejo.

El segundo problema alude a la naturaleza de los procesos no técnico-instrumentales. Éste reclama la distinción normativo/cognitivo, que a continuación abordaremos. El movimiento teórico esencial para aproximarnos al estudio sociológico de los procesos y de los hechos institucionales consiste en distinguir, dentro del fenómeno institucional, dos aspectos de la uniformidad del comportamiento y de la sanción. El primero introduce el planteamiento objetivo, propio de un observador externo, que capta las dimensiones estructurales de la acción. El segundo, el planteamiento subjetivo, que capta el comportamiento institucional desde el punto de vista interno, es decir, de un sujeto que actúa conforme a las reglas institucionalizadas. La formulación rigurosa y la elaboración sistemática de tal distinción nos aparece en las aportaciones de Talcott Parsons ${ }^{3}$.

Este planteamiento ubica los elementos de la acción humana dentro de un esquema medios-fines. El sujeto actúa persiguiendo fines y coordinando los medios para su consecu-

3 Según la primera elaboración del joven Parsons, una institución puede ser definida como «un sistema de normas regulativas, de reglas que gobiernan la acción para la consecución de fines inmediatos en los términos de su conformidad al sistema de valores últimos común en la comunidad» (1990). Por tanto, desde el punto de vista sociológico, el elemento propiamente institucional son las reglas normativas. Para Parsons, las instituciones no son un fenómeno concreto, sino un elemento analítico de él. No se trata de formas de relaciones concretas (regulares y estables), sino de un elemento de estas formas. Es cierto que la idea de institución implica modelos de comportamiento y relación regulares/estables, pero el punto crucial es su conexión con la idea de sanción (elemento normativo). 
ción. El elemento racional consiste en el razonamiento lógico que conecta medios y fines ¿Cuál es el lugar de las instituciones en este esquema? La solución de Parsons es la siguiente: la acción humana (en general) se desarrolla en complejas cadenas medios-fines, que comprenden numerosos fines intermedios, pero que, sin embargo, tienen forma no circular. Ahora, en una situación social, los fines últimos de las diferentes cadenas medios-fines - las acciones de los diversos individuos en interacción — no sólo están en una relación casual ( $y$, por tanto, potencialmente conflictiva) entre sí: de otra forma, nos encontraríamos ante la situación hobbesiana de la guerra de todos contra todos. Por tanto, debe existir, y existe empíricamente, integración de la parte intermedia de las diferentes cadenas medios-fines en términos de un sistema común de valores últimos. Pero ¿de qué forma los valores últimos están conectados a esta parte intermedia? De forma a) externa (la norma es diferente del fin específico de la acción) y b) no automática (conformar la acción a la norma implica esfuerzo de la voluntad versus inercia y pasiones, además de otros problemas cognitivos). He aquí la necesidad de las instituciones, es decir, normas regulativas, reglas que gobiernan la acción en la persecución de fines inmediatos en términos de su conformidad con el sistema común de los valores últimos de la comunidad (Parsons, 1990: 324-325).

A continuación, y de forma más explícita, Parsons (1988) ubica el problema de las instituciones en el cuadro de referencia del sistema social de acción. Más concretamente, es parte crucial de los problemas generales de la constitución de los sistemas sociales y de los fundamentos de su estructura. Y aquí se explica de qué forma las instituciones conectan valores y motivaciones, incentivando el esfuerzo voluntario de los sujetos. La cuestión es enmarcada en sus términos teóricos más generales. El sistema de acción humana tiene tres centros autónomos de organización de los propios elementos: el sistema social (de la interacción de los sujetos agentes), el sistema de la personalidad y el sistema cultural. La integración del sistema de acción siempre es un compromiso entre las tendencias a la coherencia de los tres sistemas, cada uno de los cuales realiza en sí una integración parcial. Es en este nivel donde Parsons afronta el problema central de la constitución de los sistemas sociales y de los fundamentos de su estructura: el de los requisitos funcionales.

En concreto, la interpenetración entre el sistema social y el sistema de la personalidad se centra en el problema de generar en los individuos la motivación al orden, es decir, la exigencia de motivar un número suficiente de sujetos que desarrollen las prestaciones necesarias para la persistencia y desarrollo del sistema. Ésta es una condición mínima a la que debe adaptarse el sistema social respecto a los sistemas de la personalidad. El requisito funcional de la motivación adecuada es un punto de partida primario para el concepto de institucionalización. El hecho es que las personalidades no se conforman espontáneamen- 
te a las obligaciones de rol; para esto sirven mecanismos específicos que reclaman a la estructura social, además de a la estructura de la personalidad.

La integración institucional de los elementos de la acción implica integrar las motivaciones de los sujetos y los criterios culturales normativos dentro de un tipo de sistema ordenado. Por tanto, el problema del orden es doble, planteándose, por una parte, en el plano de la comunicación y de los sistemas simbólicos y, por otra, en el plano de la reciprocidad de la orientación motivacional. Este último ha sido definido como el problema hobessiano del orden.

Es importante observar que, para Parsons, orientarse conforme a las normas no implica simplemente actuar según impulsos más o menos inconscientes, en contraste al propio interés perseguido racionalmente. La idea es más compleja: utilidad y proyección interna son formas que el sujeto utiliza para motivarse y actuar de una determinada manera. El hecho es que si los criterios y las normas regulativas son claramente compartidos, los dos aspectos de la motivación podrán armonizarse, en cuanto que un comportamiento conforme a la norma provocará una reacción positiva del otro con el que se establece la relación y, en consecuencia, una ventaja para quien actúa. Un sistema integrado es un vínculo para conformarse a modelos de valores compartidos, en el interés de los sujetos. La conformidad, por tanto, tiene una estructura doble. Cuando un modelo de valor satisface los criterios se dice que está institucionalizado. La institucionalización es la función de dos conjuntos de variables: las que inciden en la motivación y las que inciden en la participación en modelos comunes de valores. La institución es, en síntesis, un complejo de relaciones de estatus institucionalizadas, que tienen un significado estructural estratégico en el sistema social en cuestión.

Hemos observado cómo Parsons considera el problema del orden -e, internamente a él, el problema de las instituciones - bajo el doble aspecto del orden simbólico y motivacional. Ello nos advierte de la complejidad y de la multidimensionalidad de la teorización parsonsiana y del esfuerzo que demanda a sus intérpretes. Sin embargo, se puede sostener que el sociólogo de Harvard concretamente ha desarrollado su teoría desde la vertiente motivacional. $Y$ desde esta relativa unilateralidad se deriva un relevante cambio en la teoría sociológica de las instituciones. Para Parsons, institucionalizar significa que un determinado comportamiento asume valor en sí. Los valores que guían el comportamiento se reflejan en juicios valorativos, son transmitidos a través de la socialización y son experimentados por los individuos como «compromisos» (al valor). La crítica afirma que, con ello, Parsons ha minimizado los elementos cognitivos de la orientación a la acción en su mismo esquema, olvidando la cultura como objeto de orientación y cancelando los aspectos afectivos y valorativos neutrales, dados por descontado, propios del comportamiento rutinario. En consecuencia, la exploración de los aspectos cognitivo-constitutivos de la cultura representa el 
núcleo del cambio teórico del que estamos hablando. En este cuadro, la institucionalización se configura como proceso esencialmente cognitivo más que normativo; reglas y rutinas serían el material del que están hechas las instituciones. Por tanto, el llamado "cambio cognitivo» (Powell y Di Maggio, 1991) implica una desnormativización de la teoría. Las instituciones esencialmente consisten en tipificaciones que los actores no perciben y que les impulsan a confirmar una determinada imagen de la realidad y de lo que "se debe» hacer, rechazando las desilusiones y las evidencias empíricas contrarias. Ahora la teoría se ocupa de comprender cómo los individuos organizan las informaciones con la ayuda o por medio de categorías construidas socialmente. Resumiendo: desde una teoría normativa a una cognitiva de la acción; del compromiso a la rutina; de los valores a las premisas dadas por descontado; de la motivación a la lógica de seguir reglas.

El interrogante crucial es: ¿cómo es posible que significados subjetivos se conviertan en factibilidades objetivas? En el sentido de «dado por descontado», la respuesta traslada a la importancia del sentido común. Las instituciones son construidas por «una tipificación recíproca de acciones habituales por parte de determinados tipos de actores" (Berger y Luckmann, 1993): se trata de construcciones cognitivas que controlan la acción humana antes e independientemente de cualquier mecanismo o sanción específicamente pensado para mantener tales comportamientos.

La institucionalización es, por tanto, el proceso de transmisión de lo que es socialmente definido como tal y a través de lo que el significado de otro puede convertirse en parte dada por descontada de la realidad social (Zucker, 1977). Las instituciones definen qué son los hechos, la realidad social. Sólo posteriormente se pueden expresar preferencias sensatas. Sirven para construir un mundo significativo y hacerlo manipulable. Por otra parte, también sirven para exonerar a los sujetos de pensar, permitiéndoles concentrarse en aspectos relevantes de la realidad, no teniendo que definir constantemente toda situación, o bien evitando que se piense en las cosas más importantes (Douglas, 1990), objetivando nuestras decisiones en función de ellas.

Ahora bien, quedan pendientes una serie de interrogantes: ¿qué rol tienen en el orden institucional la intencionalidad y los intereses? ¿Cómo se pasa de los microprocesos al orden social, a la estructura? Más en general: hemos hablado de «cambio» para caracterizar una fase del pensamiento sociológico contemporáneo y, lo que es más importante, para revelar una distinción conceptual importante.

Los problemas planteados nos revelan que, actualmente, es necesario dotarse de una teoría multidimensional de las instituciones, una teoría que observe los diferentes planteamientos como dimensiones de una realidad compleja, es decir, como componentes del fe- 
nómeno institución. Éste aparece entonces como un fenómeno multidimensional, y tal es también el proceso que instaura las mismas instituciones. Podemos representar esta idea mediante el siguiente esquema (Lanzalaco, 1995: 47):

FIGURA 1

Las cuatro dimensiones del fenómeno institucional

Institucionalización como propiedad

Instituciones como vínculos a la acción (Commons, North, Ostrom)

Énfasis en el componente jurídico-formal (A)
Instituciones como principios regulativos (Parsons, Eisenstadt, Alford, Friedland)

Énfasis en el componente prescriptivo (L)
Institucionalización como proceso

Instituciones como modelos de comportamiento válidos y persistentes (Weber, Selznick, Huntington, Blau)

Énfasis en el componente estructural (I)

Instituciones como elementos constitutivos de la realidad social (Berger y Luckmann, Douglas, Zucker)

Énfasis en el componente cognitivo

(G)

Este esquema nos revela la concienciación respecto a la multidimensionalidad, concienciación que debe mantener la teoría para elaborar representaciones adecuadas de la realidad. El autor que lo ha propuesto ha pretendido sistematizar las posibles opciones del horizonte teórico cruzando dos variables: por una parte, objetividad/subjetividad; por otra, carácter procesual o no procesual del planteamiento. Sin embargo, en estos términos tal esquema se limita a presentar una (útil) taxonomía de planteamientos, alternativos entre sí, que subrayan los aspectos más importantes del fenómeno, pero que se basan en premisas ontológicas y epistemológicas incompatibles. La intención teórica de mantenerlos y utilizarlos permanece en el nivel de exigencia.

Sin embargo, es posible interpretar el mismo esquema mediante el esquema AGIL. Según esta interpretación, el planteamiento jurídico-formal corresponde a la función adaptativa (A), el cognitivo a la función de realización de las metas $(G)$, el estructural a la función integradora (I) y el prescriptivo a la función de mantenimiento del modelo latente (L). Entonces, los cuatro grandes planteamientos pueden considerarse como dimensiones de un fenómeno complejo — la institución social— del que ahora se puede captar la unidad. Esto implica asumir una ontología social relacional, capaz de explicar cómo se estructura lo social a 
partir de los individuos según lógicas que los superan, manteniendo abierta la relación con ellos y su dimensión de libertad. De esta forma, las instituciones son comprensibles como relaciones AGIL, que se desarrollan como procesos de objetivización a lo largo del eje estructural — que representa la regularidad y la estabilidad — y a lo largo del eje de la atribución de sentido. Es necesario comprender a fondo las implicaciones de este planteamiento. Desde este punto de vista es posible no sólo afirmar que una institución es un fenómeno cognitivo y normativo, jurídico-formal, etc., sino estudiar los intercambios entre las diferentes dimensiones. A través de estos intercambios la institución se construye (continuamente) y se mantiene. La especificación sistemática de los intercambios depende, obviamente, de la esfera institucional considerada — la familia, la democracia, el sistema educativo, etc.-.

Por otra parte, el planteamiento relacional ayuda a comprender las instituciones como construcciones sociales que «existen» y se regeneran en la historia, a través de sus intercambios internos y manteniendo relaciones significativas con los propios ambientes pre y meta-sociales. Los complejos intercambios con estas últimas dimensiones se diferenciarán según la esfera institucional en cuestión (económica, política, cultural, etc.). El esquema puede formularse de esta forma:

La institucionalización como construcción en relación a lo pre y meta-social

\begin{tabular}{|l|lc|c|}
\hline & jurídico-formal $(\mathrm{A})$ & cognitiva (G) & \\
$\begin{array}{l}\text { Ambiente } \\
\text { pre-social }\end{array}$ & & Ambiente \\
meta-social
\end{tabular}

El esquema sirve para representar a la institución como relación social, capta su funcionamiento, o bien su dinámica constitutiva interna. Ahora bien, esto expresa el modo de ser de una relación social, y ofrece una imagen de su regeneración en una fase «normal». Sin embargo, comprender la misma institución como proceso, analizando el grado de estabili- 
zación y legitimación de una institución a lo largo de cualquier eje y desde cualquier aspecto específico, requiere otros pasos teóricos.

\section{CÓMO SE GENERAN LAS INSTITUCIONES}

Tal y como se ha señalado anteriormente, las instituciones son concomitantes respecto a la misma existencia de una vida social ordenada. Sin embargo, es difícil encontrar explicaciones adecuadas de cómo originariamente emergen estos modelos de comportamiento normativamente regulados. El origen último de las instituciones aún está en penumbra.

Quien ha abordado el interrogante de la génesis generalmente ha caminado por el atajo de los planteamientos «desde el lado de la demanda»: es decir, ha interpretado el problema del «cómo se generan las instituciones» en el sentido de explicar por qué hay necesidad de instituciones; por este camino, a lo sumo, se han especificado algunas de las condiciones en las que emergen. Desde este punto de vista, la génesis de las instituciones es explicada por las necesidades individuales y sociales, por las necesidades de otras instituciones o condiciones ecológicas, demográficas, psicológicas generales. La complejidad del ambiente parece ser la condición genética y de funcionamiento de los sistemas sociales complejos. En términos orientados a los individuos, el discurso de la complejidad se traduce en el concepto de incertidumbre: las instituciones emergen «porque» es necesario reducir la incertidumbre radical de los actores, y esto puede llevarse a cabo mediante la estabilización de los comportamientos orientados a las reglas. Por tanto, la demanda de instituciones será mayor allí donde es mayor la incertidumbre que se debe afrontar y menor la capacidad (competencia) de los individuos para encarar y "calcular» racionalmente los riesgos que esta incertidumbre comporta (Heiner, 1983). Estamos ante el nexo entre acción e institución, racionalidad y orientación a la norma. Naturalmente, el problema es que la demanda por sí sola no crea su oferta. En consecuencia, las instituciones pueden o no emerger.

\subsection{La emergencia de las instituciones en el paradigma utilitarista}

La línea de trabajo dominante en el paradigma utilitarista concibe a las instituciones dentro del marco de los llamados fallos del mercado. Se entiende aquí como mercado el ámbito o espacio de las transacciones libres y espontáneas entre individuos. La teoría microeconómica ha puesto de manifiesto cómo este esquema de intercambio produce resultados que son socialmente no óptimos, en el sentido de que un grupo de individuos actuando coordinadamente obtendría resultados mejores para todos y cada uno de ellos que en ausencia de cooperación. Esta situación se puede ejemplificar en la producción de bienes colectivos, 
situación en la que los individuos particulares adoptarán un comportamiento oportunista, con el fin de apropiarse de los beneficios de la acción colectiva a un coste cero. Este razonamiento individual, generalizado a nivel de la colectividad, lleva a un nivel de provisión subóptimo, dado que ningún individuo tiene incentivos para colaborar en la producción de un bien de cuyo consumo no podrá excluirse a quienes no contribuyen, dado el problema de la indivisibilidad.

Este modelo teórico es aplicable a muchas situaciones habituales de la vida cotidiana. En ellas, la ausencia de un mecanismo de coordinación provoca resultados indeseables para los individuos. Ahora bien, ninguno de ellos tiene incentivos para apartarse de la pauta de comportamiento general, a riesgo de ser explotado por los demás miembros de la colectividad, si no existe un marco institucional apropiado. Podemos analizar este tipo de situaciones desde el punto de vista más general del problema de la cooperación entre individuos. Más aún, muchas situaciones de intercambio bilateral en la vida social también implican problemas de cooperación, dado que existe un problema importante de riesgo moral, en el sentido en que la confianza de un individuo en la contraparte puede ser violada arbitrariamente si no existe un mecanismo institucional que asegure la efectividad de los contratos y de las promesas.

La teoría económica clásica asume un presupuesto imperativo bastante fuerte, y es el hecho de que los derechos de propiedad están fijados de antemano de manera exógena y que los contratos son obligatorios. Aun así, existe otro problema no menos importante que es el de la información incompleta y asimétrica, introducido en la teoría económica por Akerlof $(1970)^{4}$. Los recursos comunales son otra área en la que se plantean problemas similares a los de la provisión de bienes públicos. En este caso, el problema no es el de la producción de los bienes, sino el aprovechamiento mismo de un bien sobre el que existen unos derechos de propiedad excluyentes, pero cuyo consumo no es perfectamente divisible ${ }^{5}$. Otro problema concomitante a los de riesgo moral y selección adversa es el de los

\footnotetext{
4 En aquellos intercambios bilaterales en los que una de las partes tiene más información sobre el objeto de la transacción que la otra, los problemas de articulación del mercado pueden llegar a su propia inexistencia. El resultado final de este problema concreto de riesgo moral es un mecanismo de selección adversa que hace que las mercancías de mayor calidad vayan desapareciendo del mercado de intercambios en la medida en que se ven afectadas negativamente por la distribución media de las calidades. También es obvio en este caso que todas las partes se beneficiarían del intercambio, pero éste no es posible en ausencia de un mecanismo de garantías obligatorias o de un sistema estandarizado que permita señalizar la calidad (Spence, 1973).

5 El problema que aquí se plantea es conocido como la «tragedia de los comunes» (Hardin, 1968) y consiste en que la sobreexplotación del recurso lleva a su propia ruina. Es evidente que todos los individuos se benefician si se introdujera una limitación sobre el aprovechamiento del recurso que lleva a resultados superiores para todos y cada uno de ellos, pero a nivel individual cada cual prefiere la sobreexplotación propia cuando los otros hacen un consumo contenido. Aquí también, la única solución posible es la introducción de un mecanismo de coordinación que asegure el comportamiento comedido de todos y cada uno de los titulares del recurso. Lo contrario lleva a la extinción del mismo.
} 
costes de transacción. Dado que los intercambios implican posibilidad de fraude oportunista, las partes se ven obligadas a establecer procedimientos de contratación complejos ex ante. De la misma manera, los posibles incumplimientos generan problemas de litigación interminables ante los tribunales, o costes de transacción ex post ${ }^{6}$.

Dos notas características son comunes a todos los planteamientos que entran dentro de esta corriente de pensamiento. En primer lugar, las motivaciones individuales siguen siendo instrumentales, es decir, no renuncian a una teoría utilitarista de la acción social. En segundo lugar, las instituciones sociales son Pareto óptimas, en el sentido de que los individuos implicados en la transacción están mejor conjuntamente después de la introducción de las instituciones. Ahora bien, el problema del origen histórico de las instituciones permanece sin una respuesta satisfactoria. Podemos expresarlo en los siguientes términos. Aunque es perfectamente asumible que todos los individuos pueden preferir racionalmente un mecanismo institucional que asegure la provisión de determinados bienes públicos, pongamos por caso el orden social, ¿qué motiva a unos individuos concretos a implicarse en el coste de generar las instituciones aun cuando podrían beneficiarse de la existencia de las mismas sin colaborar en su formación?

Una línea de argumento desarrollada por Olson (1965) plantea una solución atractiva a este problema, aunque no exenta de problemas. El punto de partida de Olson es el análisis económico del oligopolio. Se asume que en la provisión de bienes públicos el beneficio se distribuye de manera desigual entre distintos individuos. Por este motivo, hay individuos más motivados para inducir la producción de bienes públicos que serán los que más se benefician de ellos. Aun así, la producción individual de bienes públicos es socialmente subóptima. Por lo tanto, los individuos que más se benefician de los bienes públicos estarán más motivados a crear instituciones de provisión colectiva. ¿Cuál es el incentivo que tienen el resto de individuos a participar en la provisión pública? La solución de Olson a este problema derivado es ciertamente ingeniosa. El incentivo no deriva de la propia contribución al bien público, dado que la relación marginal entre la contribución realizada y el beneficio suplementario tomará un valor insignificantemente bajo en la mayoría de las situaciones. El incentivo a participar en instituciones colectivas, según Olson, deriva de la estructura de incentivos selectivos que proveen las propias instituciones. De manera que un individuo no participa en una institución por el beneficio que recibe a través de la provi-

\footnotetext{
6 En el paradigma Coase-Williamson el origen de las organizaciones modernas representa un intento de reducir los costes de transacción en el mercado libre. De este modo, las organizaciones son vistas como formas de regularización o institucionalización de transacciones o intercambios regulares en el mercado que se desarrollan en el interior de un marco institucional. Ese marco institucional abarata los costes de transacción globales, haciendo de la organización un mecanismo económico eficiente. El planteamiento desarrollado por Williamson (1975), con sus críticas y limitaciones, tiene el indudable mérito de integrar la teoría de las organizaciones en la corriente central de la teoría económica, en el intento de superar una laguna fundamental de la teoría ortodoxa en la que las organizaciones económicas eran una especie de caja negra cuyas dinámicas internas resultaban intratables.
} 
sión del bien colectivo, sino por el beneficio particular que le provee la institución a través de incentivos selectivos destinados a la captación de individuos racionalmente motivados.

Otra vía de argumentación interesante es la solución al problema de la cooperación en ausencia de instituciones. Es la vía desarrollada por Axelrod (1980), quien analiza el problema en términos de un dilema del prisionero iterativo. En este contexto la disposición a cooperar en el momento presente, en ausencia de constricciones institucionales, es una función del valor de las interacciones futuras. Axelrod establece que, en situaciones de interacciones repetitivas y frecuentes, la cooperación es autosostenida, dado que el beneficio de cooperar en el presente se ve incrementado por el beneficio futuro de una relación duradera. En este marco es probable que surjan estructuras institucionales que aseguren la cooperación de manera continua, dado que la regla de la cooperación es relativamente estable y no puede ser invadida por reglas de comportamiento no cooperativas.

De una u otra forma, el origen de las instituciones en el paradigma utilitarista remite al tema del contrato social en su versión hobbesiana y su consecuente resolución del problema del orden social. Dado que todos los individuos se encuentran mejor en un marco institucional regulado que en ausencia de él, éstos están motivados a aceptar cierta limitación sobre su libertad individual, a cambio de que esta limitación sea también aplicable al resto de los miembros de la colectividad. En este sentido, la existencia de instituciones es racional, a pesar de que sea irracional someterse unilateralmente a restricciones institucionales. Si el sometimiento es multilateral, la opción del orden social es racionalmente preferible.

Las instituciones se convierten en una forma de garantía de los derechos individuales. Fundamentalmente, el contrato social garantiza la inviolabilidad de los derechos de propiedad y la obligatoriedad de los contratos que los individuos pueden establecer sobre sus derechos legítimos, que son de otra parte los presupuestos normativo-filosóficos indispensables de la teoría racional de la acción social. Las versiones y variaciones posteriores de la teoría permiten atender a situaciones más complejas en las que se plantean otros problemas sociales. Y la opción por las instituciones se entiende como una forma de resolver dilemas individuales y colectivos en el marco de un conjunto de normas que, restringiendo determinadas libertades individuales, pueden asegurar un beneficio conjunto para cada individuo tomado aisladamente.

Una vez que las instituciones existen, el problema de la viabilidad de las instituciones, en cuanto pautas regulares de acción, se explica a partir de la estructura de incentivos y recompensas que generan. Los individuos raramente, salvo en procesos fundacionales, participan en la conformación de las instituciones o en la delimitación del marco normativo de las mismas. Por tanto, ¿por qué reciben adhesión las instituciones preexistentes en las 
cuales los individuos se ven formando parte por procesos de adscripción, como puede ser el caso de las sociedades políticas como el Estado? Según el paradigma utilitarista, las instituciones sociales son viables en tanto que mantienen un sistema de incentivos y recompensas que hace que los individuos particulares obtengan un beneficio de su encuadramiento institucional en relación al coste que supondría el abandono de la institución. La estructura de incentivos y recompensas hay que entenderla también referida al marco de las sanciones que establece la institución contra quienes contravienen sus normas. Pero estas sanciones sólo son efectivas en la medida en que los miembros de la institución tienen un incentivo particular a castigar o a aplicar las sanciones contra quienes contravienen las normas.

\subsection{Las instituciones como realidades preexistentes}

Muchas de las teorías de la génesis de las instituciones verdaderamente no hablan de cómo se generan las instituciones, sino que describen formas de acción colectiva (más o menos organizada) y regular dentro de una sociedad diferenciada en esferas muy institucionalizadas. Tales teorías confunden la generación con la regeneración o el cambio de las estructuras y de las instituciones dentro de la sociedad. Ahora bien: ¿siempre han existido las instituciones? La génesis de las instituciones, ¿es un tema que debe dejarse a los antropólogos? ¿Es posible plantear sociológicamente el problema de cómo se generan las instituciones, o este problema quizás está mal formulado, y se reconduce al de la transformación? Dicho en otros términos: los procesos del origen institucional, ¿son o no son diferentes de los de persistencia/cambio? ¿Lo que genera las instituciones es diferente de lo que las regenera (cambiándolas)?

El planteamiento que asumimos en estas páginas afirma que la teoría sociológica de la génesis y la del cambio mantienen una estrecha relación, pero no pueden resolverse la una en la otra. El punto clave consiste en comprender que la Sociología probablemente no está en situación de expresar una teoría generalizada al respecto; entonces se trata de precisar que los procesos generativos de las instituciones que podemos observar se desarrollan en el ámbito de la sociedad moderna, lo que implica un contexto social muy estructurado y diferenciado. Por tanto, debemos aceptar que la «génesis» institucional en condiciones modernas jamás se ubica en un «hipotético punto cero de la sociabilidad», sino que está insertada en un proceso de morfogénesis compleja, de elaboración estructural y cultural, que dura desde hace siglos. Al mismo tiempo observamos que, a veces, tal morfogénesis comporta la transformación de las instituciones existentes y, a veces, la génesis de instituciones nuevas; y que los procesos de creación se diferencian, al menos en parte, de los procesos de cambio. Dentro de este horizonte es posible preguntarse: ¿qué tipo de relaciones 
sociales genera la matriz de relaciones e intercambios regulares y dotados de legitimidad que llamamos instituciones?

En realidad, «partir de la existencia» no es una expresión unívoca. Existen muchas formas de «partir de la existencia» de las configuraciones institucionales dadas. Para analizarlas se puede comenzar desde una conexión fundamental: la existente entre teorías de la génesis y ontologías sociales. Las diferentes concepciones del momento generativo se presentan estrechamente ligadas a las diferentes concepciones de las instituciones en cuanto tales. ¿Cuál es la relación con el tiempo? Para quien afirma la prioridad de la estructura sobre la acción, el único nexo temporal —y genético— observable es el que conecta una estructura con la condicionada acción sucesiva. La acción va allí donde la lleva la estructura. El cambio sociocultural es, en consecuencia, un proceso en que se despliega la misma estructura, realizándose a través de la acción. En este modelo, la cuestión de la génesis de la estructura y de las instituciones no puede plantearse. Se presupone que la estructura es "eterna», o bien se debe recurrir a explicaciones extrasociológicas, a lo sumo introducidas ad hoc. Admitido que tienen un origen, las instituciones sociales no tienen un origen social $^{7}$.

Un posible planteamiento consiste en pensar la estructura y la acción como nexo de mutua constitución (Giddens, 1990). Concretamente:

a) Acción e institución son concebidas como una dualidad inseparable; la entidad relacional que se deriva — denominada dualidad de la estructura - consiste esencialmente en prácticas.

b) Preferencias y lógicas de acción de los individuos están condicionadas, pero no determinadas, ni por la racionalidad ni por el contexto institucional.

En este modelo, acción (entendida como elección libre y consciente) y estructura están copresentes en todo momento de la morfogénesis de lo social. Todo singular acto humano alcanza a la estructura consolidada, la reproduce y transforma, simultáneamente. Desde el punto de vista de nuestro problema, la crítica que se puede realizar a este planteamiento es que la estrecha simultaneidad hace imposible captar cuándo emerge una verdadera y propia innovación. Incluso aquí, la estructura es eterna, y «vive» reproduciéndose en la cir-

\footnotetext{
7 Es típico el ejemplo de Durkheim: niega que las instituciones sean recursos de los individuos con los que controlar racionalmente las circunstancias de la vida. La sociedad genera las instituciones, como representaciones colectivas, mediante el canal de las conciencias de los individuos; pero ¿qué prácticas son institucionalizadas? Las resultantes de las variables morfológicas (Durkheim, 1926). Véanse, para una lectura compatible con la que aquí se presenta, Alexander (1990b), Aron (1987) y Poggi (1973). Alusivo a la estructura de la sociedad civil, un ejemplo contemporáneo con tintes durkheimianos nos lo ofrece J. C. Alexander (1997).
} 
cularidad del proceso de estructuración. Se puede observar el momento en que deja de existir, pero no cuando tiene lugar su nacimiento.

La crítica de las precedentes posiciones ha llevado a la teoría a asumir un planteamiento dualista, por el que estructura y acción son estudiadas como principios autónomos, irreducibles el uno al otro, cuyo nexo ineludible y simétrico genera la morfogénesis de la sociedad (Archer, 1995). Estructura y acción son consideradas como interagentes en el tiempo, y específicamente se sostiene que actúan sobre espacios temporales diferenciados y no contemporáneos. Las instituciones sociales se desarrollan como una sucesión de fases «normales», en que la estructura se reproduce a sí misma, y momentos genéticos, en los que la interacción reelabora la estructura — a partir del condicionamiento estructural-, Ilegando incluso a modificarla. Por lo que respecta a la cuestión genética, no es sustancialmente diferente de los otros. Ciertamente, permite analizar un espacio temporal más extenso y conceptuar el tiempo social como composición de fases diferentes - fases «normales» y fases «innovadoras»-. Pero, en último término, el momento genético es regresión al infinito, y desaparece tras innumerables ciclos morfogenéticos ${ }^{8}$. Por tanto, no se aclara el origen de la estructura. Tan sólo es reelaborada (no creada) por la interacción, la cual depende y utiliza siempre como material la estructura (precedente).

El anterior debate se ha centrado en el problema de la relación entre estructura y acción en el proceso de institucionalización. Ahora es preciso detenerse en una particular directriz teórica que lleva a formular la teoría de las instituciones en relación a una teoría de los procesos cognitivos. Este planteamiento (Douglas, 1990) critica a las teorías de la elección racional por no haber aclarado el elemento que constituye la comunidad, la solidaridad y las mismas instituciones. Y afirma que existe una cuestión epistemológica en la base de la génesis de la comunidad, cuestión que esencialmente sería una realidad pensada, representada y mental. La tesis fundamental dice que la solidaridad depende del compartir categorías de pensamiento. Y lo explica con el hecho de que en los individuos está la exigencia de la maximización de la utilidad, pero también la necesidad de orden, coherencia y control de la incertidumbre. Las comunidades no se transforman en pequeñas instituciones, y posteriormente grandes, mediante un proceso continuo; es necesaria una paralela convención cognitiva (Douglas, 1990: 82). Por tanto, es preciso investigar el rol de los procesos cognitivos en la formación del ligamen social.

8 La sociedad jamás pierde estructura, y las personas pueden reproducirla o modificarla, pero no crearla. «Ésta es la condición humana, nacer en un contexto social (lenguaje, creencias y organización) que no hemos creado: el poder de los agentes siempre se limita a rehacer, ya reproduzca o transforme la herencia social» (Archer, 1995: 89). 
La génesis institucional como proceso cognitivo

Fase $A$

Tipo de elemento que ordena
Necesidades «mínimas» (interés común por la existentencia de una regla)
Fase $B$

Convenciones compartidas (reglas o instituciones a nivel mínimo)
Convenciones cognitivas (analogías de naturalización, en las que se fundamenta la legitimidad-racional)

Forma social

Individuos

Grupos latentes

Instituciones

Sin embargo, es necesario explicar por qué ciertas creencias, y no otras, emergen y son sostenidas en común. Más en general, se trata de examinar cómo emergen los sistemas de conocimiento. ¿Cómo nacen creencias y conocimientos compartidos? En síntesis, el proceso es descrito como una naturalización de relaciones sociales. Una institución nace cuando las reglas y los comportamientos que fija se corresponden con entidades y procesos de la naturaleza y del universo. La fórmula que hace de una idea una convención cognitiva fundamenta su legitimidad en la naturaleza y en la razón. Y esta fórmula de naturalización hace de elemento estabilizador de un orden social que no puede, de otra forma, contar con un empuje espontáneo al equilibrio.

Parece evidente que este planteamiento interpreta el interrogante sobre «cómo» se generan las instituciones de forma muy particular: el concepto de convención cognitiva no explica, desde un punto de vista social, cómo tiene lugar el proceso de institucionalización. Simplemente dice que es un ingrediente cognitivo de tal proceso y, desde el punto de vista de sus contenidos simbólicos, precisa de qué tipo de convención se trata. Sin embargo, esto contempla la estructura lógica, pero no social, del proceso. Al querer explicar la emergencia de la convención, la teoría asume un carácter marcadamente durkheimiano: la convención emerge de un proceso social (del grupo) y, a su vez, el orden social emerge del elemento cognitivo.

La apariencia cognitiva también puede subrayarse desde puntos de vista próximos a la teoría de la elección racional (Lanzara, 1997). Entonces la creación de instituciones es contemplada como un problema de aprendizaje - un problema de ubicación y de uso de recursos materiales, cognitivos y simbólicos en el tiempo por parte de los individuos- - Alternativamente, es posible que el sistema social camine hacia dinámicas de «investigación inciertas» y de excesiva inestabilidad. Esto esencialmente se explica por las contracciones de los horizontes temporales en períodos de crisis. Por tanto, el difícil equilibrio entre explo- 
ración y aprovechamiento puede conducir al proceso de institucionalización a rápidas y continuas inversiones de preferencias desde una a otra estrategia, y a un caminar errático y desconectado.

Podemos sintetizar el panorama teórico anteriormente recorrido en un esquema. En él se ubican algunos autores de referencia y sus teorías de la institucionalización en relación a las distinciones que hemos utilizado respecto a la ontología social y la definición del fenómeno institucional.

\section{FIGURA 4}

Teorías de la institucionalización en relación a las definiciones de institución

Ontología social

Visión de las instituciones

Individualismo

Holismo

Cognitiva

Lanzara, March

Douglas

Normativa

Weber

Durkheim, Alexander

Hemos observado que una teoría de la génesis institucional plantea a la Sociología grandes desafíos. Es necesario conectar estructura y acción para captar distintivamente el rol autónomo de ambas y su relación. También hemos visto, por otra parte, que los elementos cognitivos juegan un importante rol, y que desde este perfil la creación de nuevas configuraciones institucionales es un recorrido de aprendizaje accidentado y contingente. Pero, a pesar de estas múltiples dificultades, la construcción institucional tiene lugar y se trata de un proceso muy difundido. Ahora el interrogante a afrontar es el siguiente: ¿mediante qué procesos específicos la interacción reelabora la estructura en sentido creativo y no sólo transformativo?

En la génesis de una institución está clara la centralidad del momento de la interacción, en contextos de vida cotidiana, más o menos caracterizados afectivamente, o en el ámbito de los movimientos sociales. Tal interacción puede desarrollarse según modalidades y procesos diferentes. Dos son los más relevantes por sus potencialidades generativas.

I. Las formas de vida organizadas y racionalizadas pueden tener como premisa fundadora momentos irracionales (Weber, 1993; Moscovici, 1988). Una innovación puede nacer mediante procesos «calientes» de creación, y no como resultado de una evolución. Esto introduce el concepto de carisma: en Sociología este término ha sido considerado como una cualidad extraordinaria, a partir de la cual una persona está dotada de fuerzas y capacida- 
des excepcionales; tal fuerza vital permite (o hace creer permitir) instaurar relaciones íntimas con el mismo centro de la experiencia vital humana y de sus significados últimos (Shils, 1965). Por este motivo, la persona dotada de carisma se convierte en el centro de «elección» y «atracción» de los otros. El carisma tiene el poder de restaurar intensidad y vitalidad en las relaciones interhumanas. Es un singular estado de efervescencia social, afectivo e intenso. Tiene la fuerza de vencer la inercia de la costumbre; el momento carismático es, por todo ello, opuesto a las relaciones sociales «normales» y estables, a las instituciones. El carisma impone en lo social un cambio discontinuo, un nuevo sentido de las cosas. Cuando se forma una institución aparece un campo de relaciones denso e intenso, que se puede denominar el estado naciente (Alberoni, 1977). Existe en él algo de inconmensurable respecto a lo que preexiste. El carisma actúa en un tiempo social en el que lo que sucede entre los hombres tiene lugar de forma directa y subjetiva, personal. $Y$ es entonces cuando se abre la oportunidad para quien «tiene carisma» de fundar nuevas instituciones (o de renovar completamente las existentes), configurando y coagulando el consenso de los otros hombres. Por tanto, las instituciones tienen un origen, por así decir, a-histórico. De este campo social inicial, de este estado naciente, se saben muy pocas cosas. Sus propiedades conocidas son las siguientes:

- Relaciones y reglas son estrechamente fluidas.

- Los ligámenes son puramente personales (no caracterizados por poder e intereses); se trata de una comunidad afectiva.

- Existe una racionalidad propia de la acción carismática. Consiste en la capacidad de construir simbólicamente un fin lejano, el sentido compartido de las cosas.

La sociedad, en consecuencia, tiene dos estados: el normal y el revolucionario (Weber, 1993; Alberoni, 1977). Plantearse el problema de la institucionalización significa preguntarse cómo se pasa de uno a otro.

II. Junto a las creaciones institucionales inducidas por el carisma, en el nivel de la interacción existen procesos de tipo más «normal» y racional, incluso creativo. El orden también puede emerger mediante el llamado bricolage institucional (Lanzara, 1997). El bricologe es un cambio acumulativo e invisible, y por ello no necesita de la remoción de enormes recursos materiales y simbólicos suscitados en el momento carismático, sino que llega a un umbral más allá del cual genera un cambio cualitativo. Posteriormente, la interacción debe conectarse a las variables estructurales. Por una parte, el proceso presupone la emergencia de emprendedores institucionales y, por otra, la existencia de personas que están interesadas en «pagar» cualquier cosa para que la actividad de construcción institu- 
cional se realice, ofreciendo a cambio dinero u otro tipo de recursos, como apoyo político, consenso, etc., materiales o simbólicos.

Para ofrecer una imagen de síntesis, la institucionalización es observada como un momento integrador de un proceso que contempla diferenciación e integración (Eisenstadt, 1990). Dicho brevemente, la cristalización de órdenes institucionales resulta de la interacción entre: a) las más generales características estructurales de las mayores esferas institucionales; b) el desarrollo de élites de emprendedores en algunas esferas institucionales de aquella sociedad, en algunos de sus enclaves, o en otras sociedades con las que tal sociedad está conectada de cualquier forma; c) la diferencia entre las élites y sus formas específicas de comprometerse en el proceso de construcción institucional, en el que es crucial su orientación cultural, es decir, la dimensión cultural de sus actividades: confianza y solidaridad; sentido, significado y legitimación son insertados en el proceso como actividades de las élites. Podemos representar tal fenómeno con la ayuda del siguiente esquema:

FIGURA 5

Un modelo del proceso de institucionalización

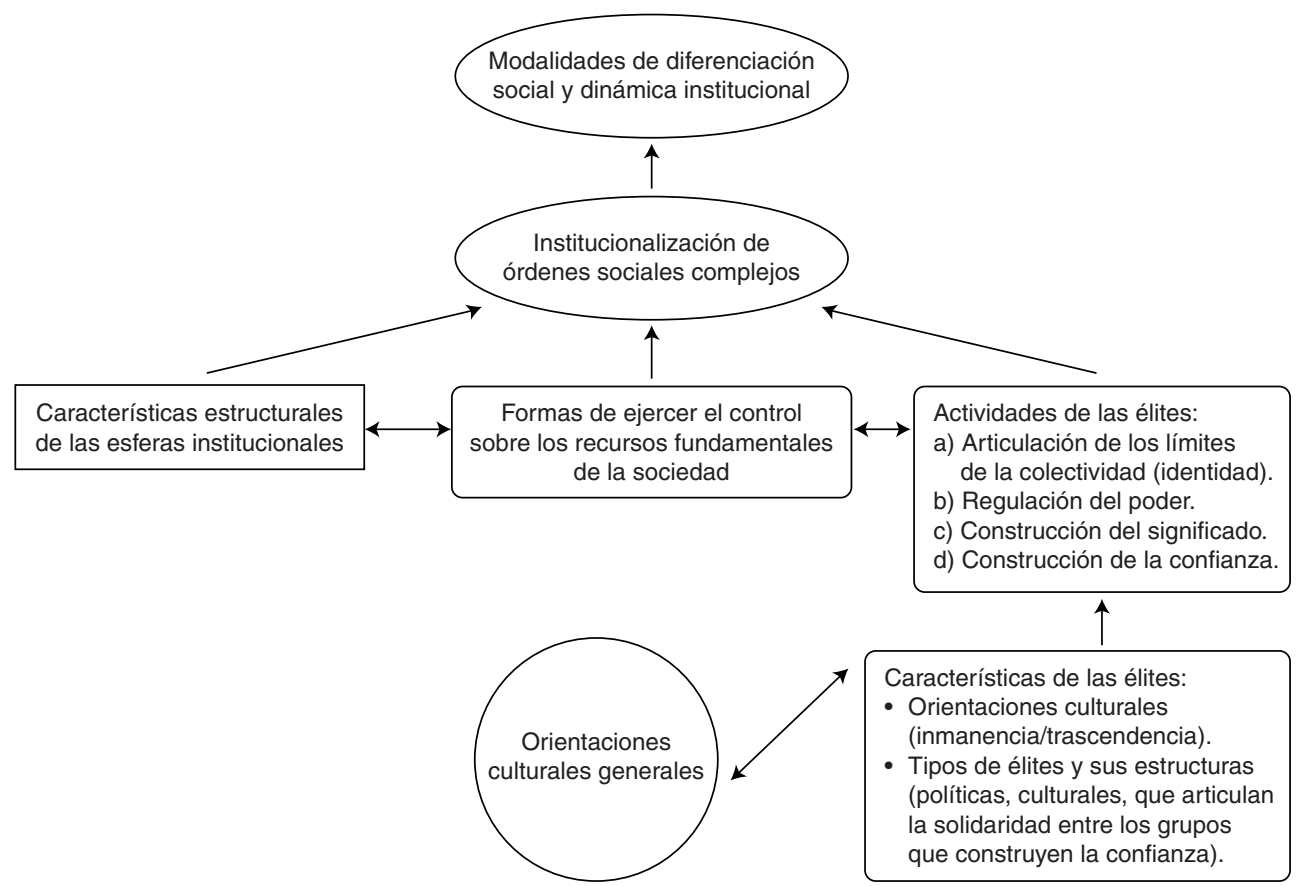


La creación de órdenes sociales complejos es el resultado de la institucionalización de la dimensión carismática del orden social, que se traduce en una forma de ejercer el control y la ubicación de los recursos fundamentales de la sociedad por parte de las élites. Tal control consiste en las siguientes actividades: manipular el acceso a los mayores mercados institucionales; convertir los recursos entre estos mercados, y detectar las normas necesarias para tal fin; controlar la producción y distribución de la información central para estructurar los mapas cognitivos de los miembros de la sociedad.

La cristalización de normas de intercambio tiene aspectos múltiples:

1) El primero es la definición de los fines fundamentales de la existencia y de la acción humanas, y de aquellos fines que son considerados indispensables para el intercambio.

2) Un segundo aspecto inicial de la institucionalización consiste en establecer las posiciones de partida de los diversos actores; posteriormente, desde ellas acceden a los recursos, y negocian y estructuran los propios intereses.

3) El tercero es la creación de diferentes medios de intercambio simbólicamente generalizados.

4) Por otra parte, está la creación y la consolidación de estructuras organizativas que facilitan el funcionamiento de los flujos de intercambio de los diferentes recursos y la circulación de los medios de intercambio simbólicamente generalizados.

5) Por último, es necesaria una triple legitimación: de las normas de intercambio, de los medios y canales de intercambio, y de los motivos o razones del intercambio.

La cristalización y la transmisión de tales normas y símbolos implican una actividad conjuntamente cognitiva y normativa. La institucionalización en su conjunto es el resultado de la interacción entre: i) características estructurales de las esferas institucionales, y ii) actividades de las élites.

\section{CÓMO SE TRANSFORMAN LAS INSTITUCIONES}

Los sistemas sociales existen en el tiempo. El pensamiento social es muy rico en reflexiones sobre el destino temporal de las instituciones humanas, sobre las características que se derivan de su inserción en la dimensión del tiempo — cósmico, además de histórico-. En concreto, si nos acercamos a la Sociología, observamos que desde su nacimiento tiene 
muy presente la conciencia de que la sociedad moderna es una realidad cambiante, contingente y frágil.

Por tanto, no resulta arriesgado decir que existen muchas formas de definir el cambio social. Y éstas se encuentran ligadas a modos de especificar lo social. El primer nudo que hay que desatar consiste en individuar un elemento distintivo de lo que es lo social. Si partimos de la idea de que lo social es relación, es decir, realidad emergente e internamente dinámica, que se desarrolla como ligamen estructural y como referente simbólico, ¿qué es el cambio? De por sí, lo social tiene el carácter de proceso. Es útil recordar que, en lo social, la distinción cambio/reproducción no coincide con la distinción dinámico/estático. Lo social es dinámico incluso cuando no produce cambio propiamente dicho. Y, sin embargo, se tiene que tener presente un concepto de cambio, aunque empíricamente constatamos que, algunas veces, las relaciones sociales pueden reproducirse tendencialmente idénticas a sí mismas (por un período de tiempo) o bien transformarse. Entonces el cambio puede ser definido como otra forma de producir relacionalmente, un modo diferente de relacionar las relaciones. Existe cambio social cuando las necesarias relaciones que definen específicamente una entidad social se forman con cualidades distintivas que difieren de las precedentes. El cambio implica una forma diferente de ordenar relacionalmente los elementos de un sistema y las relaciones entre sí.

Coherentemente con tal definición general, la teoría del cambio debe observar su objeto según modalidades específicas:

I. Ante todo, se impone un cambio en la concepción de la causalidad; un modelo definido de cómo una institución social se transforma debe incorporar la multidimensionalidad y circularidad de la influencia de los factores; los factores causales que generan procesos de cambio son múltiples y retroactúan los unos sobre los otros, haciendo más compleja la dinámica institucional.

II. Posteriormente, entender lo social como relación implica una teoría que no asuma externamente una concepción del tiempo, sino que la elabore en cuanto tiempo propiamente social y cultural (histórico); dicho en otros términos, en la base de la comprensión del cambio institucional (y en general social) está la idea de que las relaciones sociales tienen su forma de definir y construir el tiempo en que existen; por tanto, hay un tiempo social, diferente del biológico, físico o simbólico (a-histórico), aunque en relación con ellos.

III. Por último, debe tenerse en cuenta otra perspectiva. El interrogante «¿cómo se transforman las instituciones sociales?» puede entenderse en dos sentidos: a) en sentido de proceso: aquí el «cómo» quiere decir «mediante qué procesos»; b) en sentido sustantivo- 
directivo: “cómo» se transforman las instituciones quiere decir «en qué dirección» van, qué forma asumen las instituciones en el curso de su «ciclo morfogenético».

Con cierta asiduidad, la teoría del cambio social ha centrado la atención en marcos estructurales generales (Parsons, 1966; 1988) y en el análisis de situaciones históricamente específicas. El análisis de los procesos ha quedado en un segundo plano y generalmente no ha sido integrado con otras formas de conceptuar el cambio (Alexander, 1990b). La dimensión dinámico-procesual ha sido formulada o en términos preferentemente motivacionales o de socialización (Parsons, 1988) o en términos extrasociológicos muy abstractos (Durkheim, 1926; Luhmann y De Giorgi, 1992). Es en este aspecto en el que nos vamos a detener. Una primera y obvia distinción es aquella entre variables y teorías exógenas y endógenas. Las primeras subrayan la importancia de shock externos que bloquean los mecanismos de reproducción. Los factores externos a los que se alude son múltiples: la tecnología, la disponibilidad y distribución de recursos, las preferencias de los actores, las características del ambiente.

\subsection{Teorías exógenas del cambio institucional}

Se afirma que el cambio exógeno solamente puede influir mediante factores exógenos, es decir, a través de las características estructurales y culturales de la misma institución: tanto la interpenetración del cambio externo como las respuestas innovadoras dependen de los mapas cognitivos y normativos de los actores. Un cambio ambiental solamente será leído e interpretado, y se podrá rechazar modificando las estructuras institucionales, a partir del sentido que asumirá para los actores y la gama de respuestas practicables y justificables en el ámbito de un determinado horizonte simbólico. El mismo cambio, además, tiene un diferente impacto si es diverso el grado de institucionalización de los comportamientos en los que influye.

Llegados a este punto, superado cierto umbral de contestación y disfuncionalidad, la inestabilidad se traduce en cierto hundimiento repentino. Las teorías exógenas (con frecuencia de matriz económica) normalmente adoptan un modelo que podremos denominar «del equilibrio». La noción de equilibrio como tal es central a la teoría económica. La idea básica subyacente es que la realidad social atraviesa por determinadas situaciones en las que se encuentra en un punto de equilibrio, en el sentido de que ninguno de los actores individuales implicados en dicha realidad podría mejorar su posición relativa a través de un movimiento unilateral. Como puede verse, no existe ningún matiz valorativo en la definición de equilibrio. No se dice que algo sea bueno porque esté en equilibrio, sino que el equilibrio representa un estado posible de la realidad social (Schelling, 1978). 
El estudio de las instituciones desde el punto de vista del análisis del equilibrio walrasiano plantea el problema del cambio institucional como una sucesión de equilibrios en las instituciones. Las situaciones que no pueden equilibrarse de forma autogestionada llevan irreversiblemente a la desintegración de la institución, lo cual es en sí mismo un nuevo equilibrio en el que no existe la institución como tal. La noción de equilibrio sólo es compatible con una teoría del cambio institucional en la que los factores de cambio son exógenos ${ }^{9}$.

En las diferentes versiones de la noción de equilibrio, ninguno de los actores puede beneficiarse de un cambio unilateral en su comportamiento. En el caso del equilibrio de Nash, esto quiere decir que si un actor social cambia su estrategia, es decir, se comporta de otra manera, ello provocará una reacción, o cambio de estrategia, en la contraparte que hará que el primer individuo se encuentre peor después del cambio. Si todos los actores presentes en la interacción se encuentran en la misma situación, entonces estamos en presencia de un equilibrio. Un equilibrio puede ser, en efecto, socialmente no óptimo.

En un sistema de preferencias fijas, la estructura de pagos y recompensas de una determinada situación social solamente puede alterarse por un cambio en el estado del mundo, es decir, como consecuencia de la intervención de fuerzas exógenas a los propios actores sociales implicados, no necesariamente a la institución. Así pues, podemos identificar dos tipos de fuerzas principales que pueden inducir el cambio en las instituciones dentro de una teoría racional de la acción institucional. La primera de ellas es la comunicación entre actores o la coordinación. La segunda de ellas es un cambio en los elementos que definen la situación o las consecuencias de las acciones particulares, que altere la estructura de pagos y recompensas.

Respecto del primer factor de cambio, la coordinación sólo es posible o tiene sentido en el marco de una situación, o dilema social, en el que todas las partes pueden mejorar como consecuencia de un cambio combinado en las estrategias. Para que esto sea posible es necesario que exista un mecanismo de comunicación, cuyo soporte viene provisto por la propia institución. La consecuencia fundamental de este mecanismo es que permite que los propios actores sociales, a través de la comunicación, puedan cambiar las situaciones de equilibrio, haciendo así que las instituciones puedan ganar en eficiencia. Y, en este sentido, el cambio institucional evolucionará en la dirección de soluciones que sean Pareto óptimas. El segundo factor de cambio institucional es, sin duda, más importante en el marco de una teoría utilitarista del cambio en las instituciones. Los cambios en los elementos que condicionan la definición de la situación pueden ser muy diversos, aunque pueden reconducirse a tres tipos de efectos o fuerzas que pueden actuar sobre la institución.

9 Éste es un presupuesto ciertamente discutible, como muestra la creciente literatura sobre la generación de preferencias endógenas en la teoría económica (Asheim, 1997), pero es una consecuencia inevitable del presupuesto de que las preferencias son exógenas y se mantienen en el transcurso de una interacción social concreta. 
En primer lugar, habría que destacar el efecto de la tecnología social de la institución. Un cambio en la tecnología de la institución altera, evidentemente, la estructura de pagos y recompensas de los individuos implicados. Los incentivos de los individuos que interactúan en la institución operan a nivel individual y, por tanto, no es la capacidad de la institución para generar resultados socialmente óptimos lo que condiciona la adopción de una determinada tecnología, sino las ventajas estratégicas de los distintos actores implicados. Un segundo efecto, de enorme importancia, lo constituye un cambio en el entorno o en el ambiente de la institución. Si, como consecuencia de un cambio en el entorno, surgen nuevas posibilidades o formas de intercambio más ventajosas para los miembros de la institución, esto puede llevar a la desintegración de la misma, si no se operan remedios alternativos. Hay un tercer efecto que consiste en la acción de un tercero sobre la institución. En este sentido es una forma de intromisión del ambiente en la propia institución. Empíricamente, las instituciones cambian con frecuencia como consecuencia de la intervención de fuerzas extrañas a la propia institución. Es el caso típico que se da cuando existen problemas o puntos muertos que no se pueden resolver en el marco institucional previamente establecido, de acuerdo a procedimientos previamente consensuados o estabilizados ${ }^{10}$.

Una teoría racional del cambio institucional, desde el punto de vista de los actores individuales, tiene indudables ventajas epistemológicas. Pero también encierra problemas importantes en cuanto a sus efectos agregados. Algunos de ellos han sido estudiados bajo el concepto de modelos «cercanos a la racionalidad» 11 .

\subsection{Teorías endógenas del cambio institucional}

Ha sido en el terreno de las teorías endógenas donde se han elaborado los modelos más detallados sobre algunos particulares tipos de proceso. Aquí se dan mecanismos muy diferenciados. Un clásico ejemplo es el mecanismo competitivo: incluye dimensiones y fases micro y macro. Otro es el del cambio causado por la llamada permeabilidad institucional. Ambos ofrecen útiles modelos para comprender algunos específicos procesos de cambio

\footnotetext{
10 Esto es algo similar a la noción de los puntos focales, desarrollada por Schelling (1960), que se da en los que se llaman juegos de cooperación, en los que la consecución de un resultado apetecido por una de las partes depende de la colaboración de la otra parte, pero no existe un equilibrio estratégico. La intervención de una tercera parte puede orientar o focalizar el resultado de la interacción en un conjunto limitado de alternativas que sean mutuamente beneficiosas para las partes.

11 Como han mostrado Akerlof y Yellen (1985), pequeñas desviaciones de la racionalidad a nivel individual pueden tener enormes consecuencias sobre el agregado de conductas. Dados los problemas de información incompleta y asimétrica y el carácter ritualista de muchos comportamientos, un cambio en la definición de la situación puede provocar una inercia en un pequeño grupo de individuos que no siguen un patrón de comportamiento racional maximizador, sino que se dejan llevar por la inercia de los comportamientos pasados.
} 
institucional. La mayor dificultad consiste en producir un modelo generalizado que, al mismo tiempo, sea concreto y analítico. Tal empresa es muy ardua por diferentes motivos:

- En primer lugar, los tipos de procesos difieren según las esferas institucionales en que se generan.

- Por otra parte, algunos procesos sólo tienen validez descriptiva y explicativa en los casos en que las instituciones también son organizaciones. Pero esto no sucede siempre.

El cambio, entendido como excedencia de la sociedad respecto a sí misma, implica la centralidad de la relación entre estructura y acción, que se plantea como nexo problemático incluso en los planteamientos examinados. Es necesario explicar cómo se regeneran y se transforman las formas sociales a partir de un contexto de sujetos en relaciones estabilizadas y legitimadas. Hemos visto cómo se institucionalizan órdenes sociales complejos. Ahora, la premisa dice que el cambio es inherente a la misma naturaleza de los procesos de institucionalización y al funcionamiento de los sistemas institucionales. Y esto en cuanto que (Eisenstadt, 1990):

- Las normas jamás son aceptadas totalmente por toda la sociedad.

- Independientemente del planteamiento inicial de estos grupos, éste puede cambiar en el tiempo.

- Por otra parte, todo proceso de institucionalización crea nuevos grupos con intereses propios que adquieren un carácter autónomo.

- Todos estos procesos pueden intensificarse debido a la interacción entre las diferentes esferas institucionalizadas de la sociedad. Cada esfera posee valores y normas propios, que tal vez pueden imponer a los diferentes grupos peticiones contradictorias (todas tienen su propia tensión a la coherencia).

La compleja dinámica que resulta puede sistematizarse y analizarse con la ayuda de un modelo morfogenético/morfoestático (Archer, 1995). Tal modelo es un instrumento con el que captar la emergencia en el tiempo de las estructuras sociales y sus transformaciones o reproducciones (figura 6$)^{12}$.

12 Nuestra exposición no debe entenderse como una confusión o mala interpretación de las valencias del planteamiento morfogenético y el plantemiento relacional, sino como una propuesta de trabajo que busca su posible integración sistemática. Estas consideraciones también son válidas para la figura 8. 
FIGURA 6

La triple morfogénesis: estructura, cultura y acción

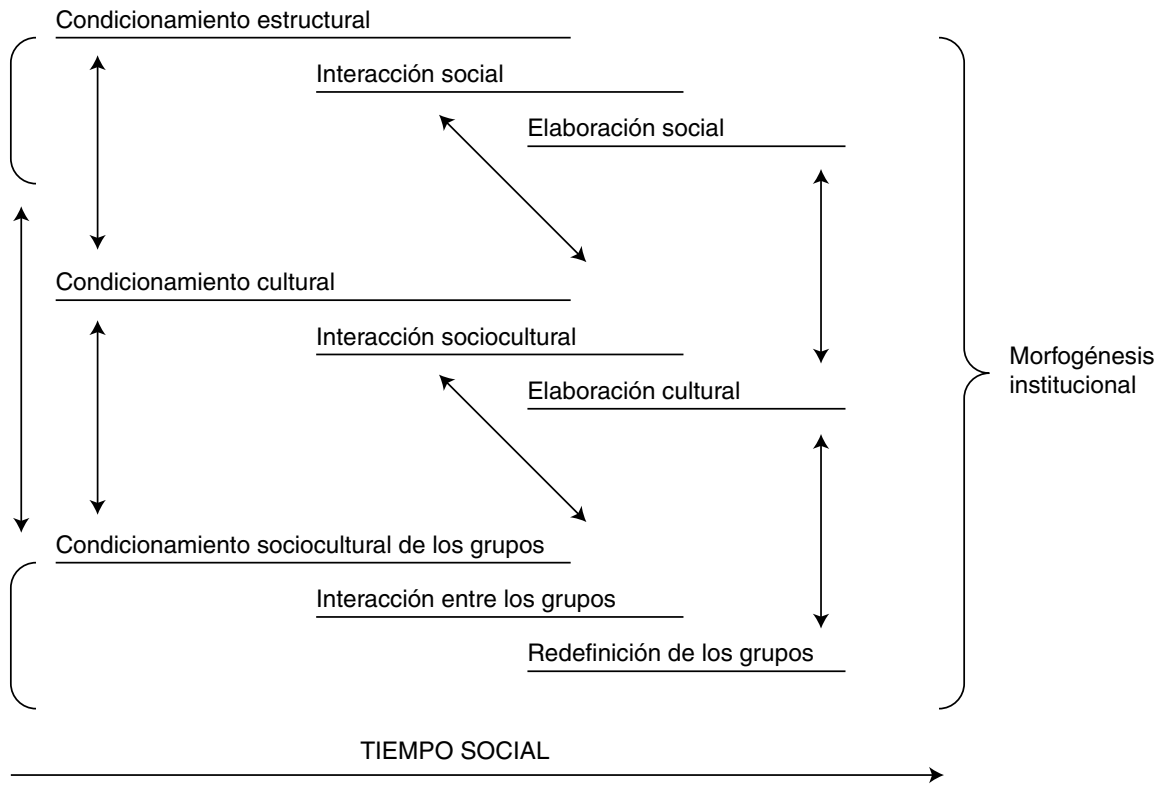

Las instituciones cambian por efecto de regularidades independientes de la voluntad de los individuos (estructuras) que, sin embargo, actúan a través de ellos. Estos últimos, a su vez, actúan libremente rechazando los vínculos estructurales y, al mismo tiempo, son transformados por aquéllos. La influencia de los factores estructurales es tanto simultánea como proyectada en el tiempo. Esto quiere decir que acción libre y condicionamiento estructural son, por una parte, inseparables y copresentes -en cuanto componentes necesarios de la estructura de la relación social-; su relación en el desarrollo del tiempo histórico-social es contingente, y puede estructurarse en fases diferenciadas. En cuanto que en la sociedad existe una especie de cambio "molecular» o "de fondo» (invisible, continuamente en acto), se darán momentos del (predominante) condicionamiento estructural y momentos de la (predominante) interacción, a través de los cuales se produce o la reproducción de las estructuras institucionales (tendencialmente) idénticas a sí mismas (morfoestasis), o su transformación (morfogénesis). Individuos y grupos, interactuando entre sí, reelaboran las estructuras institucionales, y en el proceso se transforman a sí mismos por su propio actuar. Condicionamiento estructural, interacción y elaboración estructural, tomadas conjuntamente, dan vida al ciclo morfogenético de las instituciones. 
Las fuerzas y los factores estructurales consisten en propiedades emergentes ${ }^{13}$. Las estructuras, a su vez, tienen una doble naturaleza: se trata de estructuras sociales en sentido estricto (roles e interacciones de roles) y de códigos simbólicos y a veces de valores (estructuras culturales). Cada una consiste en propiedades emergentes distintas. La acción también tiene propiedades emergentes particulares. Por tanto, en la dinámica institucional existen propiedades emergentes estructurales y culturales, y propiedades emergentes de la acción. Cada una de estas estructuras y propiedades emergentes tiene su morfogénesis, relativamente autónoma aunque condicionada por las otras dos. En realidad, el ciclo morfogenético es triple, resultado de la suma y de la intersección de tres ciclos: estructural, cultural y de la acción. El cambio o la reproducción de las estructuras institucionales se decide en la confluencia de tres conjuntos de propiedades emergentes diferentes, y de las relaciones internas y entre los diferentes ciclos. Estas relaciones son necesarias, y plantean vínculos y condiciones que hacen previsible el recorrido del cambio.

De forma más o menos explícita, las modalidades de concebir la morfogénesis de las instituciones sociales también contienen diferentes nociones del tiempo social, es decir, del tiempo en cuanto definido socialmente y condicionado por el contexto de vida de los actores de la historia, en todos sus aspectos: estructurales (sociales y culturales) y subjetivos. Las nociones de la temporalidad son un elemento muy importante para valorar la adecuación teórica de los diferentes planteamientos sobre el cambio social. Dos son los aspectos esenciales: la continuidad/discontinuidad y la dirección/a-teleología del tiempo social. Observamos que allí donde ha permanecido en la teoría sociológica la idea de que las formaciones histórico-sociales en su conjunto tienden hacia una determinada dirección, o al menos cambian según una lógica, un recorrido y dentro de coordenadas estructurales inteligibles, todo ello es actualmente descrito como empuje hacia una mayor complejidad de la sociedad, que siempre implica una mayor diferenciación de las instituciones sociales (Alexander y Colomy, 1990). Mediante la diferenciación de sus instituciones, la sociedad puede perseguir una evolución hacia una mejor adaptación a los desafíos externos (Parsons, 1982), o bien — dejando a un lado todo elemento de «progreso»— tal proceso puede no implicar una «mejor adaptación» o un incremento de la misma diferenciación, sino tan sólo un cambio en la formas de la diferenciación (Luhmann, 1982, 1998a; Luhmann y De Giorgi, 1992). Por tanto, es evidente que describir la dinámica de las instituciones y de la sociedad como diferenciación no implica haber descubierto un fin (telos) de la historia social, sino que se limita a representar un criterio para hacer interpretables los resultados y las configuraciones realizadas dentro de una dinámica más general, que trasciende las singulares fases del proceso.

${ }^{13}$ El concepto de propiedad emergente permite huir del individualismo — que no atribuye a las estructuras alguna realidad objetiva - y del holismo - que, considerándolas sustancia, atribuye a las estructuras una forma de ser impropia, reificándolas (tratándolas «como cosas» del mundo físico o biológico)—. La propiedad emergente es una propiedad relacional. 
En cuanto a la continuidad o discontinuidad del cambio, la situación de la teoría actualmente es la siguiente: «transformación». La idea de que la historia de las sociedades humanas no implique «hundimientos», "caídas» o fracturas, sino sólo graduales transformaciones, y sea en este sentido "continua», aparece en el pensamiento occidental con Alexis de Tocqueville (1989). Recientemente, la teoría ha venido subrayando el carácter restrictivo de los aspectos de continuidad y linealidad del cambio social (Hallinan, 1997). Si se piensa el cambio como continuo y lineal, sólo se describen ciertos períodos de la vida de un sistema social. Se piensa el tiempo social como continuo e indiferenciado. En este contexto, el cambio sólo puede ser gradual e imperceptible. A veces se intenta integrar en estos modelos la observación empírica. Para esta última, en los efectos se dan momentos o fases críticos, de cambio acelerado o caótico. Tales acontecimientos resultan «inconmensurables» con las fases normales. Por otra parte, se ignoran las diferentes posibles respuestas de un sistema a un derrumbamiento de grandes proporciones. De esta forma, la tesis de la continuidad de las instituciones ha sido asociada a las teorías del cambio como proceso evolutivo lineal, hacia una mayor complejidad, organización y diferenciación social, sofisticación tecnológica, etc. Sin embargo, la teoría tiende a orientarse al estudio de períodos de cambio acelerado. La visión morfogenética que hemos presentado permite captar el tiempo social no como continuo y lineal, relativamente indiferenciado, sino más bien como diferenciado a lo largo de un ciclo que prevé fases diferentes. Pero en algunos planteamientos se va más allá de una representación de este tipo y se van elaborando modelos de «catástrofe» y modelos «del caos» (Prigogine y Stengers, 1984). Estos planteamientos permiten comprender un cambio social imprevisto e inexplicable como desarrollo natural; y esto, indudablemente, representa un cambio en el pensamiento sociológico.

De forma sintética, podemos ubicar los diferentes planteamientos sociológicos a lo largo de dos ejes cartesianos: el de la continuidad/discontinuidad y el de la dirección o no en el tiempo social. El resultado aparece en la figura 7.

La nueva atención por las diversas cualidades del tiempo — que puede acelerarse o ralentizarse en fases diferentes del ciclo morfogenético, y asumir en ellas diversas encorvaduras como, por ejemplo, en el momento carismático- pone el acento en un problema muy importante. Y, por otra parte, una reflexión más meditada lleva a observar que la perspectiva institucional parcialmente esquiva estas críticas, en cuanto que desde el principio ha pretendido demostrar la continuidad mediante y más allá de las aparentes «cesuras» de la historia.

Las formas sociales a veces cambian gradualmente, a veces de manera repentina, radical y caótica. Las formas sociales, por otra parte, conservan las estructuras (interactivas y culturales) en mayor grado de cuanto las nuevas élites de emprendedores institucionales in- 
FIGURA 7

Teorías del cambio y caracteres del tiempo social

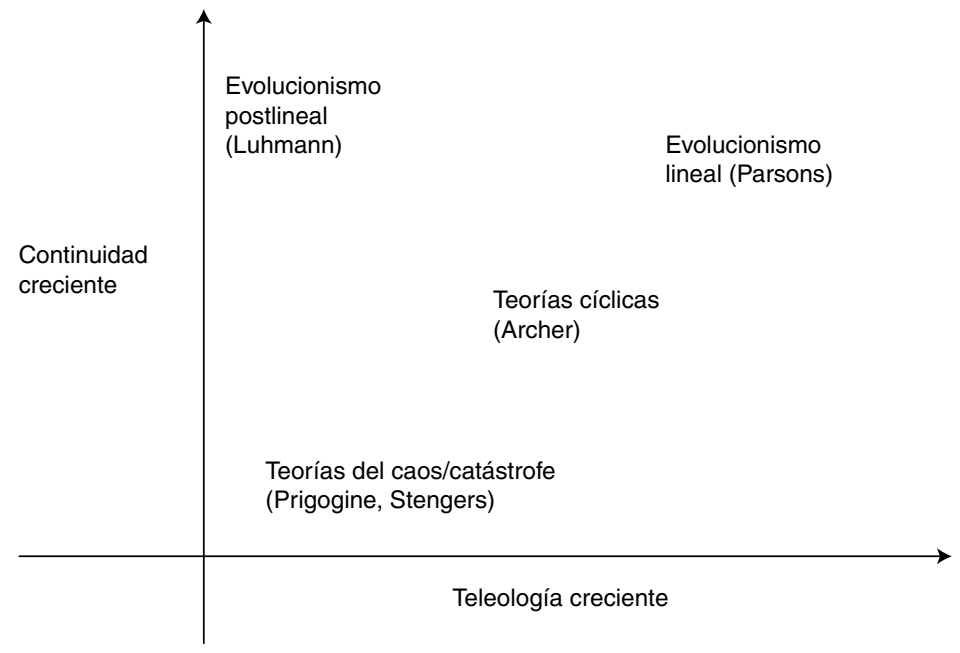

tentan hacer creer, y esto también cuando pretenden «introducir un abismo» entre el presente y el pasado. Esto cuadra con la idea de que el «momento genético» interactivo puede ser tanto carismático como esencialmente hecho de bricolaje.

¿Es posible un planteamiento que integre estos dos puntos de vista? La cuestión es compleja. Desde un punto de vista general, aquí nos limitamos a observar que es crucial la concepción de lo social en cuanto tal. La continuidad o discontinuidad del tiempo históricosocial, y con ello de los acontecimientos mediante los que la sociedad cambia, depende de una teoría de la «consistencia» de lo social tout court. Para quien concibe lo social como una sucesión de acontecimientos (comunicaciones), que pueden más o menos repetirse de forma tendencialmente similar o no (Luhmann, 1998a), la cualidad del tiempo social no puede asumir todo el espesor y todos los matices de un «tiempo de las relaciones». En síntesis, el discriminante es la concepción de la relación social. Sólo de esta forma se tiene una teoría que i) puede dar cuenta de la «ascensión» y del «declinar», más o menos rápido, pero ii) no considerándolos como acontecimientos estadísticos, o modelándolos mediante ecuaciones matemáticas, sino captando el residuo (la relación) de continuidad que tales acontecimientos comportan y que «sostiene» cualquier cambio, aunque radical, y con ello teniendo un criterio donde estudiar la «cualidad» de lo social que se modifica. 
Podemos ofrecer una representación sintética de lo tratado en los apartados 3 y 4 en la figura 8. Este esquema simplemente es una representación sintética de los diferentes momentos del ciclo de la morfogénesis institucional: tiene un valor fundamentalmente didáctico. La premisa general es una ontología social relacional. Las instituciones son relaciones sociales que tienen la forma de procesos de objetivización compleja, que se desarrollan a lo largo de las diferentes dimensiones AGIL. En estrecha relación con el nivel ontológico está el desarrollo de los ciclos morfogenéticos. El condicionamiento estructural puede dar lugar a la autodestrucción del conjunto institucional. En tal caso, el sucesivo momento de la

FIGURA 8

El ciclo de la morfogénesis institucional

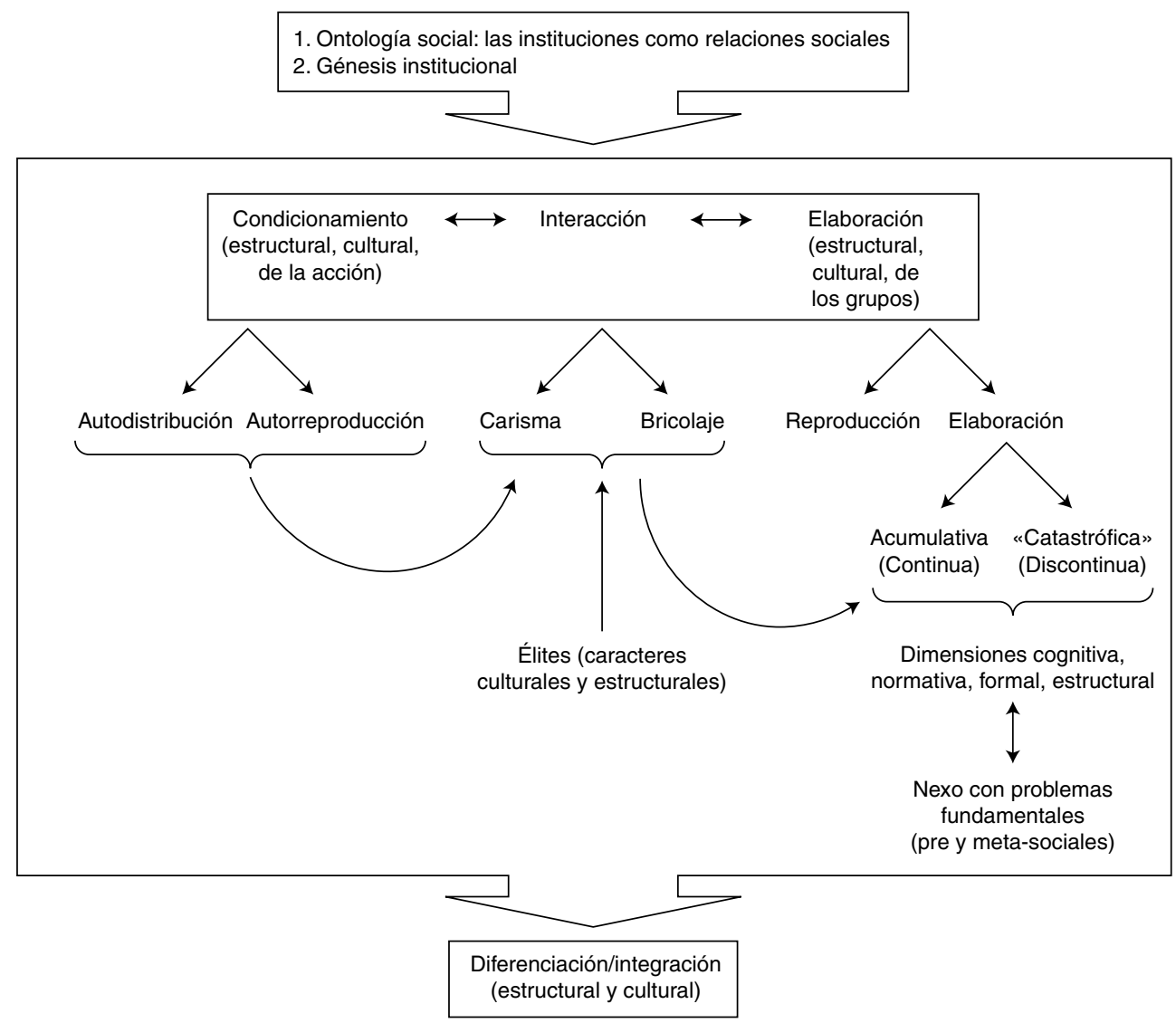


interacción asumiría —en su forma carismática y/o de bricolaje institucional— los contornos de una (nueva) "génesis», comportando una mayor discontinuidad respecto a la situación precedente. Esto implica la necesidad de movilizar una mayor cantidad de recursos (materiales y simbólicos) en el momento carismático, y/o de atravesar una fase de bricolaje más incierta y prolongada en el tiempo. En ella es crucial la actividad constructiva de las élites de emprendedores institucionales. Mediante la interacción se llega a la elaboración estructural. En este último caso los procesos de transformación se aproximan a los procesos de tipo «genético». Con ello tenemos el cuadro de una visión con carácter de proceso, dualista y unitaria, no lineal, abierta de la morfogénesis institucional.

\section{BIBLIOGRAFÍA}

AKERLOF, G. (1970): «The market for lemons: Quality uncertanity and the market mechanism», en Quarterly Journal of Economics, 84, pp. 488-500.

- (1976): «The economics of caste and of the rat race and other woeful Tales», en Quarterly Journal of Economics, 90 , pp. 599-617.

AKERLOF, G., y YELLEN, J. (1985): «Can small deviations from rationality make significant differences to economic equilibria», en American Economic Review, 74, pp. 708-720.

ALBERONI, F. (1977): Movimento e istituzione, Bolonia, II Mulino.

ALEXANDER, J. C. (1987): Twenty Lectures. Sociological Theory Since World War II, Nueva York, Columbia University Press.

— (1990a): «Commentary: Structure, Value, Action», en T. Parsons (1990: 339-345).

— (1990b): «Differentiation Theory: Problems and Prospects», en J. C. Alexander y P. Colomy (eds.) (1990).

- (1997): «La società civile democratica: istituzioni e valori», en L'etica civile alla fine del xx secolo, coordinado por P. Donati, Milán, Mondadori.

ALEXANDER, J. C., y COLOMY, P. (eds.) (1990): Differentiation Theory and Social Change. Historical and Comparative Perspectives, Nueva York, Columbia University Press.

ARCHER, M. S. (1995): Realist social theory: the morphogenetic approach, Cambridge, Cambridge University Press. ARON, R. (1987): Las etapas del pensamiento sociológico, Buenos Aires, Siglo XX.

ASHEIM, G. B. (1997): «Individual and collective time-consistency», en The Review of Economic Studies, vol. 64, pp. 427-443.

AXELROD, R. (1980): The evolution of cooperation, Nueva York, Basic-Books.

BERGER, P. y LUCKMANN, T. (1993): La construcción social de la realidad, Buenos Aires, Amorrortu.

CAVALLI, A. (1996): «Instituzione», en Enciclopedia delle scienze sociali, Roma, Istituto della Enciclopedia fondata da Giovanni Treccani, vol. V, pp. 122-134. 
DE LEONARDIS, O. (1990): I/ terzo escluso. Le istituzione come vincoli e come risorse, Milán, Feltrinelli.

DONATI, P. (1991): Teoria relacionale della società, Milán, Angeli.

DOUGLAS, M. (1990): Cómo piensan las instituciones, Madrid, Alianza.

DURKHEIM, E. (1912): Les régles de la méthode sociologique, París, Félix Alcan.

— (1926): De la división du travail social, París, Félix Alcan.

EISENSTADT, S. N. (1968): «Social Institutions, I: The Concept», en D. L. Sills (ed.), International Encyclopedia of the Social Sciences, Nueva York, MacMillan, pp. 409-421.

- (1969): «Carisma e istituzioni: Max Weber e la sociologia moderna», en Studi di sociologia, VII, III, pp. 211-240.

- (1990): Modes of Structural Differentiation, Elite Structure, and Cultural Visions, en J. C. Alexander y P. Colomy (eds.) (1990).

ELSTER, J. (1997): El cemento de la sociedad: las paradojas del orden social, Barcelona, Gedisa.

GALLINO, L. (1993): «Istituzione», en ídem, Dizionario di sociologia, Turín, Utet, pp. 387-390.

GARFINKEL, H. (1967): Studies in Ethnomethodology, Englewood Cliffs, N.J., Prentice-Hall.

GIDDENS, A. (1990): La constitución de la sociedad: bases para la teoría de la estructuración, Buenos Aires, Amorrortu.

GORDON, W. (1992): «The Implication of Process», en Journal of Economic Issues, 26, pp. 891-899.

HALLINAN, M. (1997): «The sociological study of social change», en American Sociological Review, 1, pp. 1-11.

HARDIN, G. (1968): «The tragedy of the commons», en Science, 162, pp. 1243-1248.

HEINER, R. A. (1983): «Origin of Predictable Behavior», en American Economic Review, 73, pp. 560, 595.

LANZALACO, L. (1995): Istituzioni organizzacioni potere. Introduzione all'analisi istituzionale della politica, Roma, NIS.

LANZARA, G. F. (1997): «Perché è difficile costruire le istituzioni», en Rivista italiana di scienza política, XXVII, 1, pp. 3-48.

LUHMANN, N. (1982): The differentiation of society, Nueva York, Columbia University Press.

- (1990): The Paradox of System Differentiation and the Evolution of Society, en J. C. Alexander y P. Colomy (eds.) (1990).

- (1998a): Complejidad y modernidad: de la unidad a la diferencia, Madrid, Trotta.

— (1998b): Sistemas sociales: lineamientos para una teoría general, Barcelona, Anthropos.

LUHMANN, N., y DE GIORGI, R. (1992): Teoria della società, Milán, Angeli.

MARCH, J. G. (1991): «Exploration and Exploitation in Organizational Learning», en Organization Science, 2, 1, pp. 71-87.

MARCH, J. G., y OLSEN, J. P. (1997): El redescubrimiento de las instituciones: la base organizativa de la política, México, Fondo de Cultura Económica. 
MOSCOVICI, S. (1988): La machine à faire des dieux, París, Fayard.

NORTH, D. C. (1993): Instituciones, cambio institucional y desempeño económico, México, Fondo de Cultura Económica.

OLSON, M. (1965): The logic of collective action, Cambridge: Harvard University Press.

OSTROM, E. (1991): «Rational Choice Theory and Institutional Analysis: Toward Complementarity», en American Political Science Review, 85, pp. 237-243.

PARSONS, T. (1964): «Evolutionary Universals in Society», en American Sociological Review, 29, pp. 339-357.

— (1966): Societies. Evolutionary and Comparative Perspectives, Englewood Cliffs, N.J., Prentice-Hall.

— (1968): La estructura de la acción social, Madrid, Guadarrama.

- (1978): Action Theory and the Human Condition, Nueva York, Free Press.

- (1982): El sistema de las sociedades modernas, México, Trillas.

- (1988): El sistema social, Madrid, Alianza.

- (1990): «Prolegomena to a theory of social institutions», by Talcott Parsons, with prologue and commentary, en American Sociological Review, 55, 1990, pp. 313-345.

POGGI, G. (1973): Immagini della società. Saggi sulle teorie sociologiche di Tocqueville, Marx e Durkheim, Bolonia, II Mulino.

POWELL, W. W., y DI MAGGIO, P. J. (eds.) (1991): The New Institutionalism in Organizational Analysis, Chicago \& London, University of Chicago Press.

PRIGOGINE, I., y STENGERS, I. (1984): Order Out of Chaos, Nueva York, Bantam Books.

PURDY, D. (1988): Social Power and the Labor Market, Londres, MacMillan.

SCHELLING, T. C. (1960): The Strategy of Conflict, Cambridge, Harvard University Press.

- (1978): Micromotives and Macrobehavior, Nueva York, W. W. Norton and Company.

SHILS, E. A. (1965): «Charisma, Order, and Status», en American Sociological Review, XXX, pp. 199-213.

SIMMEL, G. (1986): Sociología, Madrid, Alianza.

SPENCE, M. A. (1974): Market signaling, Cambridge, Harvard University Press.

TOCQUEVILLE, A. de (1989): El Antiguo Régimen y la Revolución, Madrid, Alianza.

WEBER, M. (1993): Economía y sociedad, Madrid, Fondo de Cultura Económica.

ZUCKER, L. (1988): «Where Do Institutional Patterns Comme From? Organizations as Actors», en ídem (ed.), Institutional Patterns and Organizations, Cambridge, Mass., Ballinger.

— (1991): «The Role of Institutionalization in Cultural Persistence», en W. W. Powell y P. J. Di Maggio (eds.) (1991). 
Analysed in this paper are the dynamics of the generation and transformation of social institutions. Two basic paradigms are studied and compared. The utilitarian framework or rational choice theories, according to which institutions are an attempt to overcome market failures through institutional mechanisms that lead to socially optimum situations, in the sense that they are preferable for the individual protagonists involved. Theories of a more sociological or culturalist nature, on the other hand, emphasize the importance of the cultural component of institutions, as well as their socio-historical determinants that evolve through complex social processes. While the former provide theoretically contrastable solutions for a range of limited problems, the latter analyse deeper problems, although at the risk of producing less conclusive results. In particular, the difference between both conceptions of social institutions become clear when the factors that give rise to the development of institutions, as well as the processes through which institutional frameworks change and evolve in response to different factors, are analysed.

Key words: Social Institutions, Cultural Rules, Rational Choice, Social Change. 